
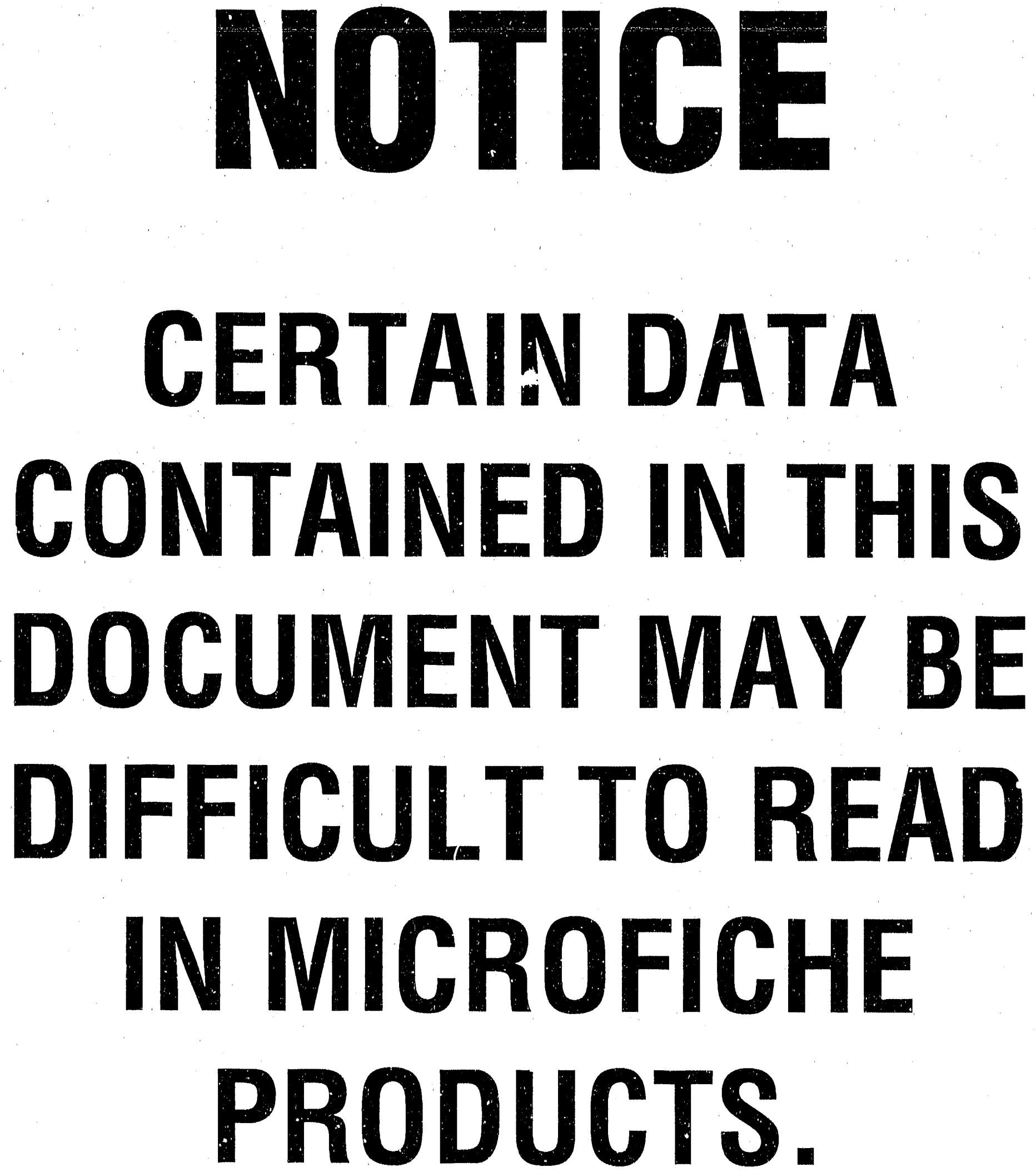
$G A-A--20181$

DE9 1001316

\section{RECENT RESULTS FROM DIII-D AND THEIR IMPLICATIONS FOR NEXT GENERATION TOKAMAKS}

by

J.L. Luxon, G. Bramson, K.H. Burrell, N.H. Brooks, D. Buchenauer, ${ }^{1}$ R.W. Callis, T.N. Carlstrom,

C. Challis, ${ }^{2}$ M.S. Chu, S. Coda, ${ }^{3}$ A.P. Colleraine, J.C. DeBoo, B. De Gentile, ${ }^{4}$ J. De Haas, ${ }^{5}$ E.J. Doyle, ${ }^{6}$

J.R. Ferron, R. Freeman, T. Fukuda, ${ }^{7}$ A. Futch, ${ }^{8}$ A. Fyaretdinov, ${ }^{8}$ G. Giruzzi, ${ }^{4}$ P. Gohil, Yu. Gorelov, ${ }^{8}$

C.M. Greenfield, R.J. Groebner, W. Heidbrink, ${ }^{9}$ D.N. Hill, ${ }^{5}$ R. Hong, W. Howl, C.L. Hsieh, G.L. Jackson, R.A. James, ${ }^{5}$ S. Janz, ${ }^{10}$ T. Jensen, R. Jong, Y. Kamada, ${ }^{7}$ A.G. Kellman, J. Kim, H. Kubo, ${ }^{7}$ T. Kurki-Suonio, ${ }^{11}$ L.L. Lao, R. La Haye, E.A. Lazarus, ${ }^{12}$ T. Lehecka, ${ }^{6}$ B. Leikind, S.I. Lippmann, B. Lloyd, ${ }^{13}$ J. Lohr, T.C. Luce, N.C. Luhmann, Jr., ${ }^{6}$ M.A. Mahdavi, H. Matsumoto, ${ }^{7}$ G. Matthews, ${ }^{13}$ M. Mayberry, B. Mills, ${ }^{14}$ C.P. Moeller, T.H. Osborne, D.O. Overskei, W.A. Peebles, ${ }^{6}$ P.I. Petersen, T.W. Petrie, C. Petty,

R. Philipona, ${ }^{6}$ J. Phillips, R. Pinsker, P.A. Politzer, M. Porkolab, ${ }^{3}$ G.D. Porter, ${ }^{5}$ R. Prater, M.E. Rensink, ${ }^{5}$ J. Rodriguez, ${ }^{4}$ G. Sager, M.J. Schaffer, D.P. Schissel, J.T. Scoville, R.P. Seraydarian, T.C. Simonen, R.T. Snider, B.W. Stallard, ${ }^{B}$ R.D. Stambaugh, H. St. John, R.E. Stockdale, E.J. Strait, P.L. Taylor, T.S. Taylor, P.K. Trost, V. Trukhin, ${ }^{8}$ J. Wight, J. Winter, ${ }^{15}$ and D. Wroblewski ${ }^{5}$

This is a preprint of an invited paper to be presented at the Seventeenth Conference on Controlled Fusion and Plasma Heating, June 25-29, 1990, in Amsterdam, The Netherlands, and to be printed in the Proceedings.

Work supported by

U.S. Department of Energy

Contract DE-AC03-89ER51114

${ }^{1}$ Sandia National Laboratories, Livermore.

2 JET Joint Undertaking, EC.

${ }^{3}$ Massachusetts Institute of Technology.

${ }^{4}$ Association EURATOM-CEA, Tore Supra, Cadarache, France.

${ }^{B}$ Lawrence Livermore National Laboratory.

${ }^{8}$ University of California at Los Angeles.

7 Japan Atomic Energy Research Institute, Japan.

${ }^{8}$ Kurchatov Institute, Moscow, USSR.

${ }^{9}$ University of California at Irvine.

${ }^{10}$ University of Maryland.

${ }^{11}$ University of California, Berkeley.

12 Oak Ridge National Laboratory.

${ }^{13}$ Culham Laboratory, UK.

${ }^{14}$ Sandia National Laboratories, Albuquerque.

${ }^{15}$ institute of Plasmaphysics, KFA, Jülich, FRG.

\section{GENERAL ATOMICS PROJECT 3466} JULY 1990

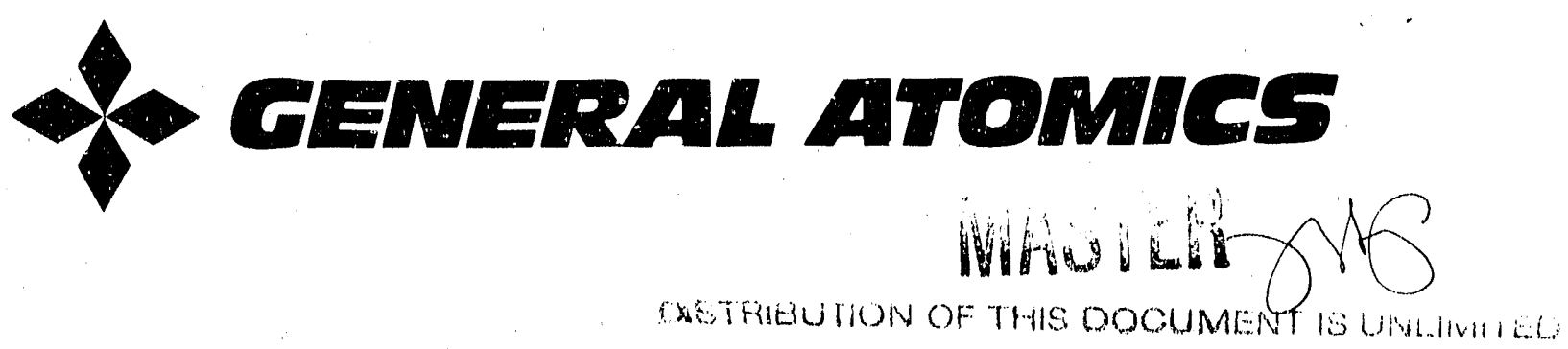


RECENT RESULTS FROM DIII-D AND THEIR IMPLICATIONS FOR NEXT GENERATION TOKAMAKS

J.L. Luxon, G. Bramson, K.H. Burrell, N.H. Brooks, D. Buchenauer, ${ }^{1}$ R.W. Callis, T.N. Carlstrom, C. Challis, ${ }^{2}$ M.S. Chu, S. Coda, ${ }^{3}$ A.P. Colleraine, J.C. DeBoo, B. De Gentile, ${ }^{4}$ J. De Haas, ${ }^{5}$ E.J. Doyle, ${ }^{\theta}$ J.R. Ferron, R. Freeman, T. Fukuda, ${ }^{7}$ A. Futch, ${ }^{5}$ A. Fyaretdinov, ${ }^{8}$

G. Giruzzi, ${ }^{4}$ P. Gohii, Yu. Gorelov, ${ }^{8}$ C.M. Greenfield, R.J. Groebrer, W. Heidbrink, ${ }^{9}$

D.N. Hill, ${ }^{5}$ R. Hong, W. Howl, C.L. Hsieh, G.L. Jackson, R.A. James, ${ }^{5}$ S. Janz ${ }^{10} \mathrm{~T}$. Jensen,

R. Jong, ${ }^{5}$ Y. Kamada, ${ }^{7}$ A.G. Kellman, J. Kim, H. Kubo, ${ }^{7}$ T. Kurki-Suonio, ${ }^{11}$ L.L. Lao, R. La Haye, E.A. Lazarus, ${ }^{12}$ T. Lehecka, ${ }^{8}$ B. Leikind, S.I. Lippmanı, B. Lloyd, ${ }^{13}$ J. Lohr,

T.C. Luce, N.C. Luhmann, Jr., ${ }^{6}$ M.A. Mahidavi, H. Matsumoto, ${ }^{7}$ G. Matthews, ${ }^{13}$ M. Mayberry, B. Mills, ${ }^{4}$ C.P. Moeller, T.H. Osborne, D.O. Overskei, W.A. Peebles, ${ }^{\theta}$ P.I. Petersen,

T. W. Petrie, C. Petty, R. Philipona, ${ }^{6}$ J. Phillips, R. Pinsker, P.A. Politzer, M. Porkolab, ${ }^{3}$

G.D. Porter, ${ }^{5}$ R. Prater. M.E. Rensink, ${ }^{5}$ J. Rudriguez, ${ }^{4}$ G. Sager, M.J. Schaffer,

D.P. Schissel, J.T. Scoville, R.P. Seraydarian, T.C. Simonen, R.T. Snider, B.W. Stallard, ${ }^{5}$ R.D. Stambaugh, H. St. John, R.E. Stockdale; E.J. Strait, P.L. Taylor,

T.S. Taylor, P.K. Trost, V. Trukhin, ${ }^{8}$ J. Wight, J. Winter, ${ }^{15}$ and D. Wroblewski ${ }^{5}$

General Atomics, San Diego, California USA

${ }^{1}$ Sandia National Laboratories, Livermore USA

2 JET Joint Undertaking, EC.

${ }^{3}$ Massachusetts Institute of Technology, USA

${ }^{4}$ Association EURATOM-CEA, Tore Supra, Cadarache FRANCE

${ }^{5}$ Lawrence Livermore National Laboratory, Livermore USA

${ }^{6}$ University of California at Los Angeles, USA

7Japan Atomic Energy Research Institute, JAPAN

${ }^{8}$ Kurchatov Institute, Moscow USSR

${ }^{9}$ University of California at Irvine, USA

${ }^{10}$ University of Maryland, USA

${ }^{11}$ University of California, Berkeley USA

${ }^{12}$ Oak Ridge National Laboratory, USA

${ }^{13}$ Culham Laboratory, UK

${ }^{14}$ Sandia National Laboratories, Albuquerque USA

${ }^{15}$ Institute of Plasmaphysics, KFA, Jülich, FRG

\section{ABSTRACT}

Recent results from the DIII-D tokamak have provided significant contributions to the understanding of many of the elements of tokamak physics and the application of this understanding to the design of next generation devices including ITER and CIT. The limitations of magnetohydrodynamic stability on the values of plasma beta (the ratio of kinetic pressure to the containing pressure of the magnetic field) that can be attained has been experimentally demonstrated and found to be described by existing theory. Values of beta (10.7\%) well in excess of those required for proposed devices (ITER and CIT) have been demonstrated. Regimes of confinement (H-mode) have been established that scale favorably to proposed next generation devices, and experimerits demonstrating the dependence of the energy confinement on plasma size have been completed. Understanding of confinement is rafiily developing especially in the areas of bulk transport and the role of turbulence in the plasma edge. Key experimental results in areas of plasma transport and edge plasma phenomena are found to be in agreement with theories based on short wavelength turbulence. Control of the divertor heat loads and impurity influx has been demonstrated, and new progress has been made in the understanding of plasma edge phenomena. Experiments with ion Bernstein wave heating have not found regimes in which these waves can produce effective central ion heating. Electron cyclutron current drive experiments have demonstrated $70 \mathrm{kA}$ of driven current in $100 \mathrm{kA}$ discharges. 


\section{KEYWORDS}

Tokamak, Fusion, Plasma Physics, Plasma

\section{INTRODUCTION}

The DIII-D research program has made significant contributions to understanding the physics and technical issues facing the fusion energy program and specifically the needs of the next generation fusion devices, e.g. CIT, the Compact Ignition Tokamak being designed in the U.S. program, and ITER, the International Thermonuclear Experimental Reactor being designed internationally.

The DIII-D program has the long term focus of demonstrating non inductive current drive at high beta with good confinement; these are key ingredients for a fusion energy power source. Key to this program has been the demonstration of substantial beta values and the understanding of beta limits, and the establishment of good confinement. Establishing and maintaining a suitable plasma-boundary interface is an important element in maintaining adequate confinement and substantial progress has been made in understanding and controlling the boundary region in divertor plasmas. The remaining key ingredient for a steady state reactor is non-inductive current drive, and we have been developing the necessary current drive tools, including developing suitable. If power coupling systems. Collaborations in pursuit of these goals with other laboratories and universities internationally and nationally have helped make a wealth of resources and ideas available to the DIII-D program.

Values of beta needed for operation of next generation devices and viable reactors have been demonstrated in DIII-D, and a solid understanding of the underlying physical mechanisms and the associated limitations has been developed. Beta values as great as $10.7 \%$ have been demonstrated in plasmas with reduced toroidal field $(0.8 \mathrm{~T})$ and values of $5.2 \%$ have been demonstrated at full field $(2.1 \mathrm{~T})$. In general the maximum attainable beta values have been limited by confinement and heating power and not stability. The observed peak beta values are found to be consistent with accepted theory. The Troyon-Sykes theory predicts the limiting value of $\beta$ to be proportional to $I / \mathrm{aB}$ where $\mathrm{I}$ is the plasma current, $\mathrm{B}$ the toroidal field, and a the minor radius [Troyon (1984); Sykes (1983)]. Values of $\beta=3.5 \mathrm{I} / \mathrm{aB}$ have heen achieved in DIII-D over the range $0.5 \leq 1 / \mathrm{aB} \leq 2.6$. Under somewhat less general conditions with more peaked current distributions, higher values have been attained with $\beta=5.0 \mathrm{I} / \mathrm{aB}$ having been attained at $\mathrm{I} / \mathrm{aB}=$ 1.1.

Loss of vertical stability coupled with a subsequent current quench as part of a disruption has been identified as producing high attached currents fowing from the plasma boundary into the vessel wall. These currents result in turn in higher forces on the vessel than expected from inductive models for current transfer from the plasma to the walls.

Particular emphasis has been given to the understanding of plasma confinement. Progress has heen made in demonstrating that confinement levels needed for next generation devices can be attained. The specification of the double null divertor configuration for CIT and ITER has helped motivate detailed study of these configurations. Regimes of good confinement ( $\mathrm{H}$-mode) have been reliably established over a wide variety of conditions and the parametric dependences have been determined. The dependence of confinement on physical size has been directly assessed for the first time in collaboration with JET with the result that the global energy confinement time in the interval following the $\mathrm{H}$-mode transition and prior to the first ELM increases with major radius as $R^{1.5}$. An effort is underway with a larger group of tokamaks to extend this scaling to include aspect ratio in joint experiments with other laboratories. Edge charge exchange recombination and density fluctuation diagnostics specific to the understanding of transport and the plasma edge region have been installed, and detailed understanding of the characteristics of the discharge especially at the transition into the $\mathrm{H}$-mode confinement state is emerging.

The importance of understanding the plasma boundary region and the plasma wall interface has emerged as a key issue in designing I'TER and CIT. The use of divertor configurations allows physical separation of the core plasma, the plasma boundary layer, and the high heat flux region of plasma-material interaction. This affords unique opportunities to understand and control the interaction of these regions. Careful management of the ELMs (edge localized modes) resulted in $\mathrm{H}$-mode discharges with $10 \mathrm{~s}$ duratinn demonstrating that $\mathrm{H}$-mode confinement is suitable for future long pulse devices. Characterization and modelling of the boundary layer has progressed with the addition of new edge plasma diagnostics including measurements of edge temperature and boundary Langmuir probe measurements. These data are being used to validate ind improve existing models of the boundary. Heat loads per unit area in the DIII-D divertor target region 
(up to $4 \mathrm{MW} / \mathrm{m}^{2}$ ) are comparable :o those anticipatcd in ITER. Techniques are being developed to actively manage the heat flow to the divertor target. Divertor sweeping has been used to spread the heat over a larger area reducing the peak heat load by a factur of three, and experiments with gas injection into the divertor boundary region have reduced the heat flow to the target plates by a factor of two to three. Hardware for an advanced divertor configuration is presently being installed in the machine to investigate and develop the potential of the divertor conflguration [Mahdavi (1990)].

Current drive is an important ingredient in the world-wide evolution tıwards d steady-state tusion reactor. The DIII-D program is working to understand and develop suit shle current drive techniques. Current drive experiments using 1.2 MW of ECH power launched from the high field side of the plasma resulted in $70 \mathrm{kA}$ of driven current in a $400 \mathrm{kA}$ discharge. These results are consistent with calculations made with a bounce-averaged Fokker-Planck code. Neutral beam heated discharges with $I=500 \mathrm{kA}$ and $14 \mathrm{MW}$ of power have attained $\beta_{\mathrm{p}}=5.1$ and $\epsilon \beta_{\mathrm{p}}=1.8$. These discharges have high bootstrap currents and beam driven currents, contributing about a third and a half of the total current respectively.

The DIII-D tokamak is a non-circular cross section device capable of a wide rar.ge of plasma configurations [Luxon ('1985)]. Single - and do tblenull divertor discharges have been ompared directly with regards to coninement, stability, and plasma boundary interaction. The cross section of the device is shown in Fig. 1 ; it is characterized by excellent access for diagnostics and auxiliary hardware, which allows a wide range of experiments to be carried out. The device has achieved $3 \mathrm{MA}$ plasma currents in the divertor configuration which is the capability of the present compliment of power supplies. The device parameters are summarized in Table 1.

Auxiliary heating and current drive power is provided by neutral beam, ECH, and ICH heating systems. Up to $20 \mathrm{MW}$ of neutral beam power is available in deuterium discharges with ion energies of up to $80 \mathrm{keV}$. The injection angle provides a significant component in the direction parallel to the plasma current Colleraine (1985) Kim (1987)]. Recent optimization for operation in deuterium has resulted in the increase from $14 \mathrm{MIW}$ to the $20 \mathrm{MW}$ power level. Up to $1.7 \mathrm{MW}$ of $\mathrm{ECH}$ power is available at $60 \mathrm{GHz}$. This system is currently configured to launch waves in the $\mathrm{X}$-mode from near the midplane on the high field side of the discharge. Up to $2 \mathrm{MW}$ of $\mathrm{ICH}$ power $(30-60 \mathrm{MHz})$ is also available and has recently been used with an antenna designed to launch ion Bernstein waves.

The demonstration that confinement in $\mathrm{H}$-mode deuterium discharges improved substantially over that in hydrogen led to the addition of a radiation shield enclosure to the torus hall. This enclosure provided an additional shielding factor of about 300, and has allowed routine operation with deuterium plasmas. The resultant in crease in plasma energy confinement and neutral beam power output has significartly increased the peak plasma parameters that hove been obtained in the device. This has allowed the research program to be carried out over a wide range of plasma parameters with limits approaching those needed for an ignition device. The peak plasma parameters attained are summarized in Table 2.

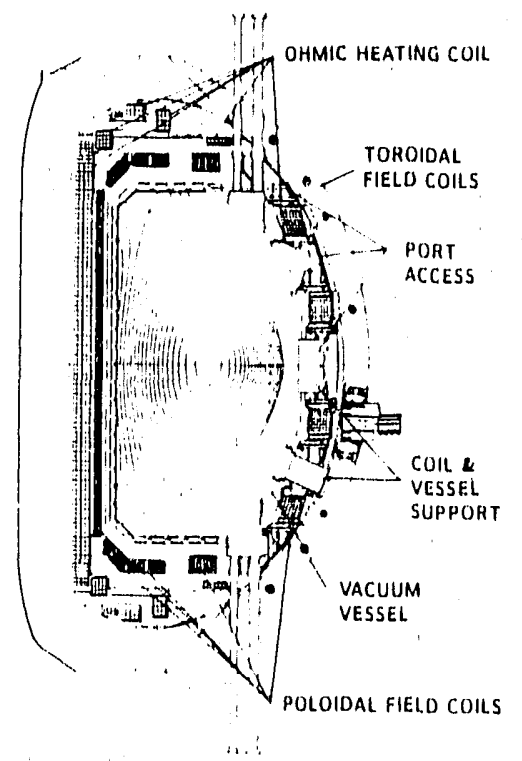

Fig. 1. Cross section of DIll-D with Hiux surfaces of a double-null divertor discharge superimposed.

Table 1. DIII-D Capabilities

\begin{tabular}{lll}
\hline & Present & $\begin{array}{l}\text { Proposed } \\
\text { Upgrades }\end{array}$ \\
\hline Major radius & $1.67 \mathrm{~m}$ & \\
Minor radius & $0.67 \mathrm{~m}$ & \\
Maximum toroidal field & $2.2 \mathrm{~T}$ & \\
Available OH flux & $12 \mathrm{~V}$-sec & \\
Maximum plasma rurrent * & $3.0 \mathrm{MA}$ & $3.5 \mathrm{MA}$ \\
Neutral beam power & $20 \mathrm{MW}$ & \\
RF power (electron) & $1.8 \mathrm{MW}$ & $7 \mathrm{MW}$ \\
RF power (ion) & $2 \mathrm{MW}$ & $10 \mathrm{MW}$ \\
Current flattop & $5 \mathrm{~s}$ & $10 \mathrm{~s}$ \\
(divertor at 2 MA) & & \\
\end{tabular}

- Divertor uperation; limiter operation of $3 \mathrm{MA}$ achieved ind 5 MA design. 
Table 2. DIII-D Achieved Parameters (not simulataneous)

$\begin{array}{ll}1 / \mathrm{a} B & 3.3 \\ \beta_{\mathrm{T}}(0) & 16 \% \\ \left\langle\beta_{\mathrm{T}}\right\rangle & 10.7 \% \\ \beta_{\mathrm{p}} & 5.1 \\ \epsilon \beta_{\mathrm{p}} & 1.8 \\ \bar{n}_{\mathrm{e}} & 1.4 \times 10^{20} \mathrm{~m}^{-3} \\ T_{e}(0) & 5 \mathrm{keV} \\ T_{\mathrm{i}}(0) & 17 \mathrm{keV} \\ W & 3.6 \mathrm{MJ} \\ T_{\mathrm{E}}\left(P_{\text {HEAT }}=2.8 \mathrm{MW}\right) & 0.34 \mathrm{~s} \\ n_{\mathrm{e}} T_{\mathrm{E}} & 0.39 \times 10^{20} \mathrm{~m}^{-3} \mathrm{keV} \mathrm{s} \\ n_{\mathrm{e}} \mathrm{T}_{\mathrm{i}} T_{\mathrm{E}} & 1 \times 10^{20} \mathrm{~m}^{-3} \mathrm{keV} \mathrm{s} \\ \mathrm{H}-\text { mode duration } & 10.3 \mathrm{~s}\end{array}$

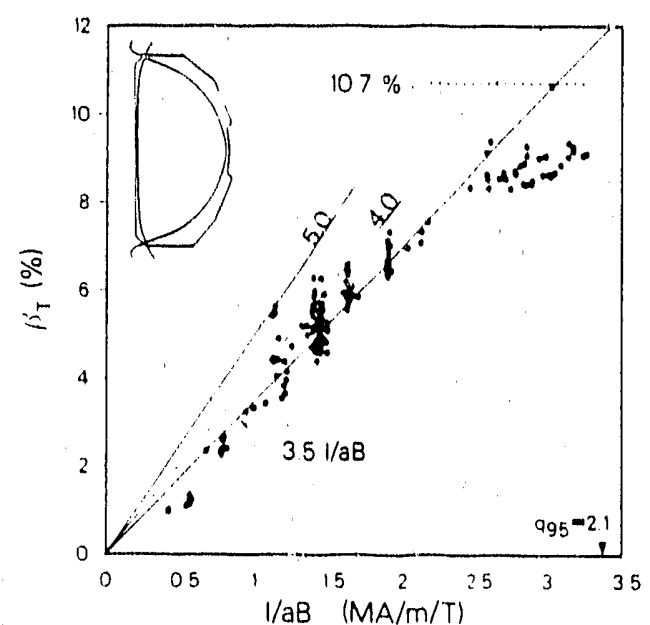

Fig. 2. The achieved beta value as a function of I/aB for $k a D$ DIll-D double-null divertor dis. charges reaching high $\beta_{N}$. A typical plasma configuration is inset.
The remainder of this paper presents summaries of recent results urganized according to plasma stability, confinement, divertor and edge physics, current drive, of heating physics, and a summary.

\section{PLASMA STABIL.ITY}

The combination of the good confinement and high neutral beam power afforded by deuterium operation along with operation with high current double null divertor discharges has illowed remarkable markable values of toroidal beta $\beta_{\mathrm{T}}=$ $\left(\int \mathrm{P} d V / V\right) /\left(\mathrm{B}^{2} / 2 \mu_{0}\right)$ and normalized beta $\beta_{N}=$ $\beta_{\mathrm{T}} /(\mathrm{I} / \mathrm{aB}) \% \mathrm{mT} / \mathrm{MA}$ to be achieved [Ferron $(1990 \mathrm{a}, \mathrm{b})\}$. Here, $\mathrm{P}$ is the plasma pressure and $V$ is the plasma volume. Discharges with values of $\beta_{\mathrm{T}}=10.7 \%$ have been obtained with elongation of 2.35 , near the vertical stability limit of the device [Lazarus (1990)]. Fol more typicai elongations of 2.0 , values of $\beta_{\mathrm{T}}=9.3 \%$ have been achieved in double null divertor discharges with the highest values of normalized current $2.7<\mathrm{I} / \mathrm{aB}<3.25$ and up to $20 \mathrm{MW}$ of neutral beam power at toroidal fields of $B=0.8 \mathrm{~T}$. Values of $\beta_{\mathrm{T}}=5.2 \%$ have been obtained at full field of $2.1 \mathrm{~T}$ with $\mathrm{l} / \mathrm{aB}=2.0$ and attaining a maximum plasma energy of $3.6 \mathrm{MJ}$.

The highest value of $\beta_{N}$ achieved to date is $\beta_{N}=$ $5.0 \% \mathrm{~m} \cdot \mathrm{T} / \mathrm{MA}$ at $\mathrm{I} / \mathrm{aB}=1.1$, which substantially exceeds the coefficient usually assumed for Troyon-Cykes scaling (Troyon (1984); Sykes (1983)). The values of beta that have been attained for a large number of discharges in DIII-D are displayed as a function of $\mathrm{I} / \mathrm{a} \mathrm{B}$ in Fig. 2. Only double null divertor discharges are included, and $a$ is held constant at approximately $0.62 \mathrm{~m}$. These discharges were obtained over a wide range of plasma conditions with various levels of con. finement and available neutral beam power. The attained beta value is not necessarily limited by stability, The simplified Troyon-Sykes scaling anticipates that the maximum value of $\beta_{N}$ that can be attained is a constant $C_{\beta}$. Previous work has identified operating limits corresponding to values of $\mathrm{C}_{\theta}$ from 2.8 to 3.5 (Stambaugh (1985); Keilhacker (1985); McGuire (1987); Okabayash (1987)\}. The results presented here demonstrate that values of $C_{B}$ at least 3.5 can be obtained over a wide range of plasma current. Values approaching $\mathrm{C}_{\mathcal{\beta}}=5.0$ have been achieved experimentally and are expected theoretically for optimal plasma profiles.

A significant number of single null discharges has also been operated at high beta values. The most significant factor differentiating between the stability limits of single null and double null discharges has been that the double null discharges can be operated at considerably higher values of $\mathrm{I} / \mathrm{aB}$ (3.4 vs 2.5) within the constraint on the safety factor $q_{95}>2$ owing to large plasma size and increased triangularity. The highest value obtained in single null discharges is $\beta_{\mathrm{T}}=7.4 \%$.

Stability theory for ideal infinite- $n$ hallooning and low- $n$ kink modes has been used to evaluate the stability of a wide range of dischiarges. Here we will consıder two examples, a high $\beta_{\mathrm{T}}$ and a high $3_{N}$ discharge [Ferron (1990)]. Inpt.i for the stability calculation is obtained by using measured temperature and density profiles along with the magnetic data to determine a self-consistent equilibrium Lao (1985)]. The discharge with $\beta_{N}=5.0$ is found to be close to the calculated 
ballooning mode heta limit as in illustrated in Fig. 3(a). The experimentally measured pressure gradient is near the gradient for marginal ballooning mode stahillty at all radil. The marginally stable value of $\beta_{\mathrm{T}}$ is $6.3 \%$ which is to be compared to the measured value $\beta_{\mathrm{T}}=5.9 \%$. The equilibrium is calculated to be stable to external kink modes with a wall included at 1.5 a (well beyond both the vessel wall and the apparent radius of the poloidal coils) and only marginally stable without the wall. Similarly, a discharge with $\beta_{\mathrm{T}}=9.3 \%$ with $\mathrm{I} / \mathrm{aB}=2.9$ was evaluated with respect to stability. The calculated ballooning mode stability limit was $12 \%$ and a substantial portion of the plasma volume $(0.4<\rho<0.8)$ was found to be well below the stability limit. [Fig. 3(b)]. The discharge was fou'd to be below the kink mode stability limil without a wall present.

Increasing the vertical elongation of the plasma can increase the attainable current and hence increase the $\beta_{\mathrm{T}}$ limit, but also can introduce axisymmetric $(n=0)$ instabilities [Lazarus (1990)]. Work with elongated discharges with low triangularity has shown that rigid body stability adequately describes the achievable plasma onditions with relatively high internal inducisnce $\left(\ell_{i}=1.5\right)$. Discharges were operated at $90 \%$ of the ideal MHD axisymmetric vertical mode limit, and elongations of up to 2.35 were atw tained. These studies identified that control of these modes is best achieved using coils on the inside major radius of the plasma above and below the midplasie. Higher elongations can be reached with increased triangularity, but with the consequence that non-rigid $(m / n=3 / 0)$ modes are also introduced. With increased triangularity, ideal stability calculations are required to correctly evaluate the stability of the discharge. For current profiles typical of DIII-D, we have been able to achieve maximum elongations of 2.5 .

The loss of vertical stability can lead to substantial forces on the vacuum vessel and in-vessel components owing to attached currents in the plasma boundary flowing through the vessel wall across the toroidal field (Jensen (1989)). MHD equilibrium models were developed providing for "attached" currents in the plasma boundary region outside the last closed flux surface and continuing through the vessel wall [Jensen (1989)]. These currents have beer identificd both by the analysis of plasma magnetic data following loss of vertical instability using this MHLD model [Lao
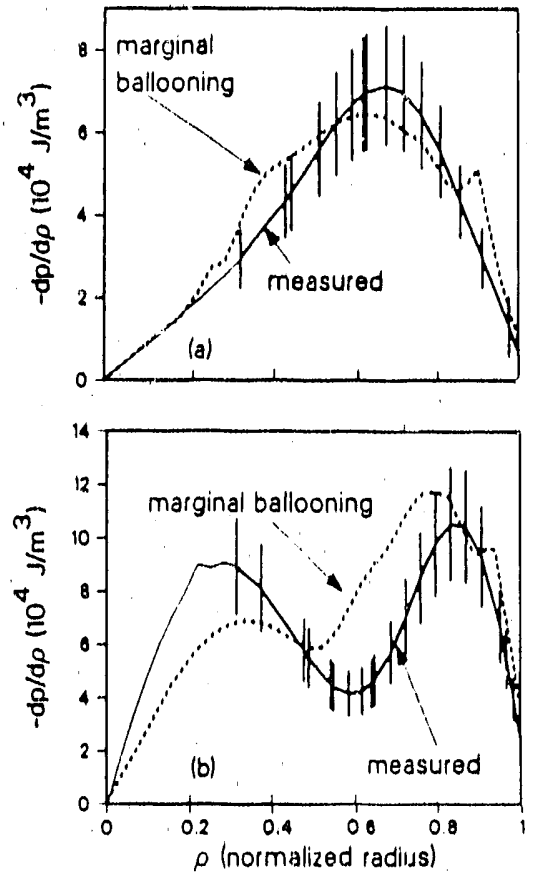

Fig. 3. Radial pressure gradients from the experimental MHD equilibrium fit (solid line) arid the calculated ballooning mode stability lim. it (dashed lii,u). (a) A discharge vith $\beta_{N}=$ 5.0; (b) a discharge with $\beta_{T}=9.3$ (1990)! and by direct measurement of the cur-

rent flowing into the wall at the interface [Strait (1990)]. Currents of up to several hundred kiloamperes were measured in 1.0 me sampere discharges (Fig. 4). These vessel currents contain a substantial poloidai component which interacts with the toroidal field and produce forces substantially in excess of those anticipated on the basis of induction alone. The calculated forces resulting from the measured currants account for the observed motion of the vacuum vessel to within the measurement uncertairty (20\%) [Strait (1990)].

\section{CONFINEMENT}

Detailed studies of confinement in deuterium discharges have been carried out, including the dependence of the total energy corfinement time of $\mathrm{H}-$ mode discharges on plasina current and power, the scaling of confinement with characteristic device size parameters (done in conjunction with other laboratories), studies of the transition into $\mathrm{H}$-mode, and detailed studies of the underlying confinement. H-mode discharges are obtained over a wide range of conditions in single-null, couble-nuil, and limiter discharges with neutral beam, electron cyclotron and ohmic heating. Energy confinement in deuterium discharges has been found to be consistently superior to that found in hydrogen and thus most of the work reported here was carried out with deuterium. 

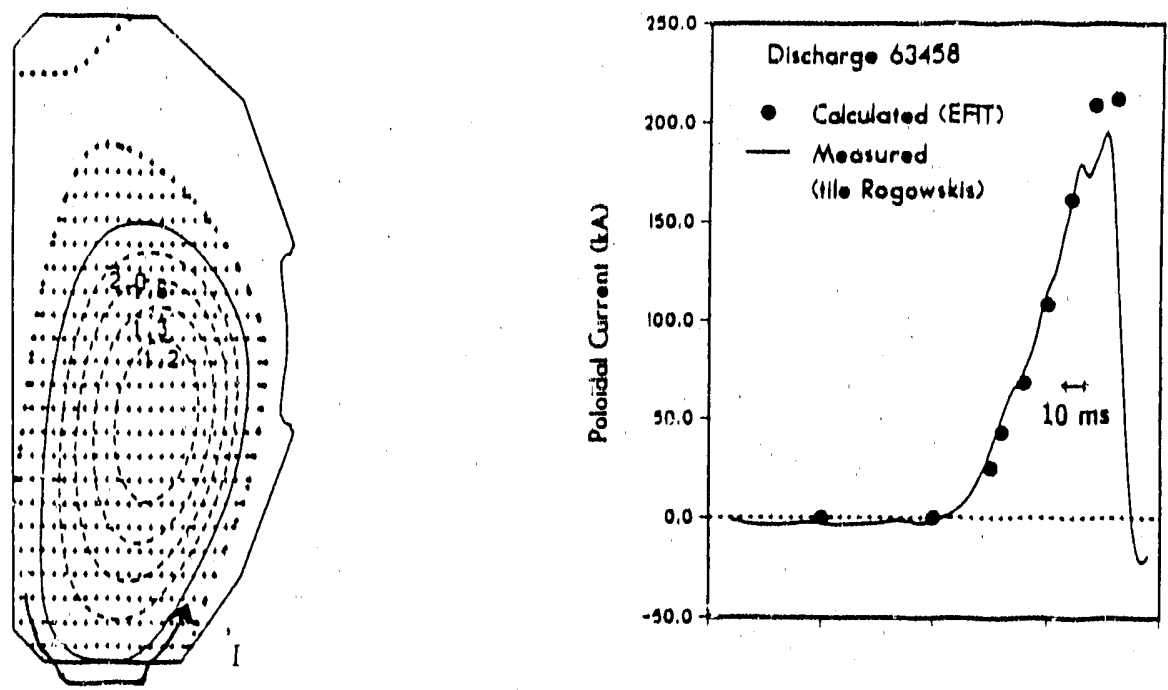

Fig. 4. Substantial vessel forces are produced by currents from the plasma through the wall following disrup. tions. (a) Plasma equilibrium during a disruption while the plasma is moving vertically downward. Closed flux surfaces are showen (solid and broken !ines) along with the sheath region outside of the last closed flux surface (solid line). (b) The current through the vessel wall in the floor region from both the magnetic analysis and the tile currerit measurements.

Experiments to study the power and current scaling of single null divertor 11 -mode discharges have been summarized previously [Burrell (1989)]. For discharges with 1 MIA plasina current, confinement is seen to rise from $150 \mathrm{~ms}$ with ohmic power (L-mode) to about $240 \mathrm{~ms}$ with $1.5 \mathrm{MW}$ of power ( $\mathrm{H}$-mode) and then fail with increasing power as $\mathrm{P}_{\mathrm{T}}^{-0.37}$. Confinement is seen to rise linearly with current for the discharges at a rate of $120 \mathrm{~ms} / \mathrm{MA}$. This linear increase of confinement with current doesn't extend to the highest currents. At the highest plasma currents $(\mathrm{L} / \mathrm{B} \geq 1$ ), confinement is found to become constant with increasing plasma current [Burrell (1989)]. Confinement has been compared in single-null and double-null divercor discharges with 2 .MA plasma currents with the result that corfinement was found to be comparable.

When ECH power is used to produce the $\mathrm{H}$-mode, the energy confinement time is independent of the resonance location normalized to the minor radius $\rho_{\text {res }}$ over the range $0.4<\rho_{\text {res }}<0.7$, and it is consistent with the observed linear dependence of confinement on current for neutral beam injection. The observed conflnement times are slightly less than that observed for neutral beam injection with equal power. This is consistent with part of the energy being stored in the fast ion population in the neutral beinn case.

A program has begun in conjunction with other laboratories to understand the dependence of H-mode confinement on plasma dimensional parameters. Initially, a comparison of single-null discharges with similar shapes was made between DIII-D and JET at a magnetic field of $\sim 2.1 \mathrm{~T}$ Schissel (1990)|. This gives an assessment of the dependence of confinement on size from the $1.6^{7} \mathrm{~m}$ major radius of DIII-D to $2.35 \mathrm{~m}$ for $\mathrm{JET}$, but no understanding of the role of aspect ratio sirce both devires have the same aspect ratio. The comparison was made during the ELM-free phase following the $\mathrm{L}$ - to $\mathrm{H}$-mode transition in order to mitigate the role of differing types of ELM behavior between the two devices $(F: g .5)$. The combined result of the two data sets was that $\mathrm{H}$-mode confinement is characterized by

$$
\tau_{\mathrm{E}(\mathrm{sec})}=0.106 \mathrm{P}_{\mathrm{T}}^{-0.4 \theta}(\mathrm{MW}) \mathrm{I}_{\mathrm{p}}^{1.03}(\mathrm{MA}) R^{1.48}(\mathrm{~m})
$$

This result gives similar dependences on power and current to the previous DIII-D H-mode results and for the first time quantifies the size dependence.

Comparisons of thermal and angi' 'momentum transport have been made in neutral beam heated $\mathrm{H}$ - and L-mode dischurges i birell (1990). For this study, a regime of low density high 


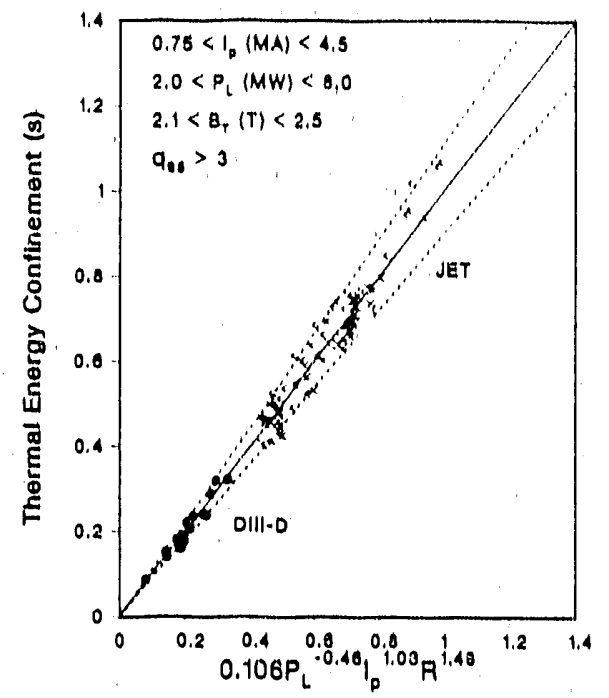

Fig. 5. Comparison of confinement in DIII-D and JET ELM-free H-mode discharges to the calculated functional dependerice.

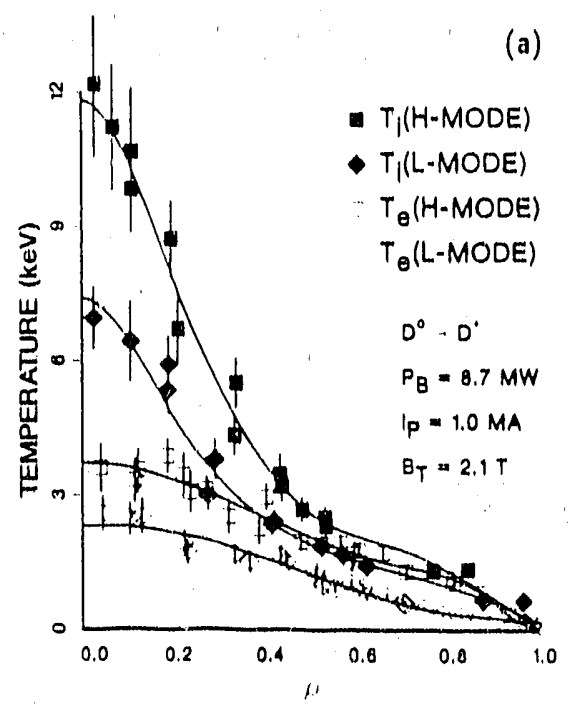

temperalure operation was chosen in order to minmize the role of the electron-ion exchange term in the transport analysis. Studies were carried out using discharges of similar cross-sectional shape at density of $3.5 \times 10^{19} \mathrm{~m}^{-3}$ with $I_{p}=1 \mathrm{MA}$, $B=2.1 \mathrm{~T}$ and an injected power of $3.7 \mathrm{MW}$. Central ion temperatures of $12 \mathrm{keV}$ were obtained in these studles along with central electron temperatures of $4 \mathrm{keV}$. Other plasmas operating in this mode with higher neutral beam injectlon power have obtained lon temperatures of $17 \mathrm{keV}$. In or. der that the density be maintained low for the $\mathrm{H}$-mode discharges the analysis was clone during the ELM free phase following the transition, ne. cessitating a time-dependent analysis. Doublenull divertior $\mathrm{H}$-mode discharges were compared to limiter L-mode discharges to obtain discharges with internal flux surfaces of nearly identical elongation (1.8).

The bulk transport of energy and angular momentum is significantly lower for $\mathrm{H}$-mode plasmas than for L-rrode. The temperature profiles have similar shapes, but the central temperatures increase by a factor of about $1.3 \mathrm{in} \mathrm{H}$-mode (Fig. 6). The density profiles are broad in both

Fig. 6. (a) Electron and ion temperature radial profiles; (b) angular rotation speed profile for the hot-ion $H-$ mode and L-mode plasma.

cases, but the $\mathrm{H}$-mode density is p.rticularly flat in the center with steep gradients at the edge. The toroidal angular rotation speed profiles are similar in shape ind quite peaked at the center, but they differ in magnitude by a factor of 1.8. The electron and angular momentum diffusivities $x_{e}$ and $x_{\phi}$ show dramatic improvements in $\mathrm{H}$-mode of aboui a factor of three throughout the plasma (Fig. 7). The ion diffusivity $\chi_{i}$ exhibits a decrease in the interior region during H-mode and no discernable change in the outer region.

These results can be interpreted in terms of a number of different theories. The value of $x_{1}$ inside of $\rho=0.3 \mathrm{in}$ the hot ion $H$-mode agrees with the predictions of Chang.Hinton neoclassical theory Chang-Hinton (1982)!, but the values of $\chi_{\theta}$ and $\chi_{\phi}$ are much larger every where than predicted. Drift waves can also be driven by emperature gradients (ITG modes) and would give $x_{i}$ about 

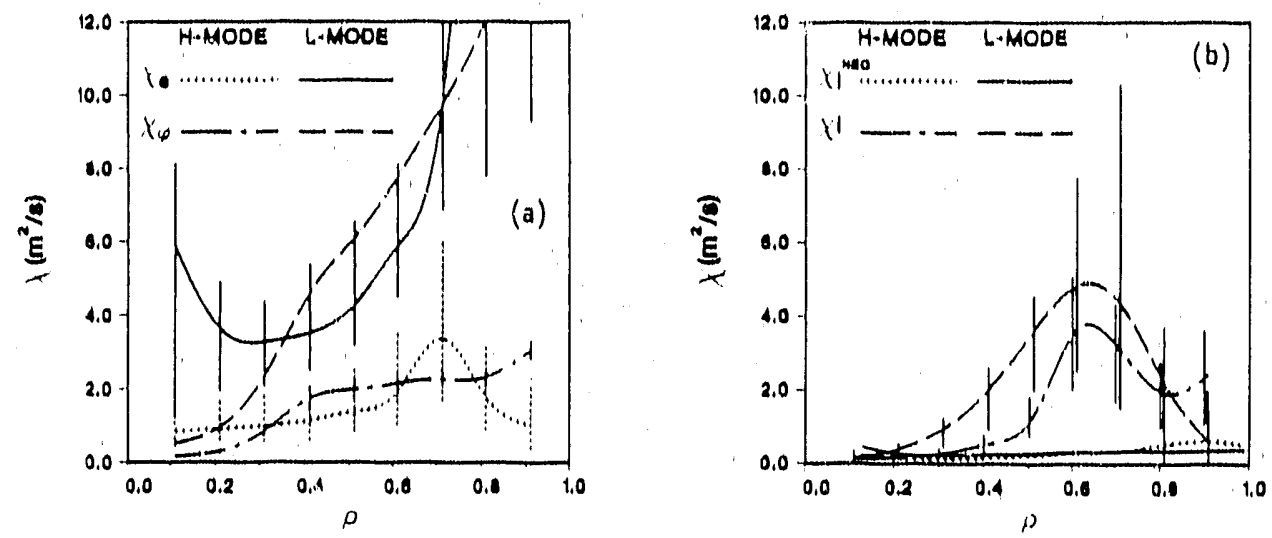

Fig. 7. (a) Electron thermal diffusivity and angular momentum diffusivity as a function of raclus in the bulk of the hot -ion L-mode and $\mathrm{H}$-mode plasmas; (b) Inferred and neoclassical ion thermal diffusivities as a function of radius in the bulk of the hot-ion L-mode and $\mathrm{H}$-mode plasmas.

equal to $\chi_{\phi}$ (Dominguez (1987)j. This is consistent with the data for the outer region of $\mathrm{H}$-mode discharges but is somewhat at disagi eement with the data in the central region $(\rho=0.3)$. However, the usual picture of ITG-driven turbulence is that the normalized ion temperature gradient scale length $L_{\mathrm{T}_{i}} / R$ drops to the critical value for the onset of turbulence and is then clamped there by the turbulence (Romanelli (1980)). This quantity has been calculated for typical discharges, and while it is below the threshold indicating potential instability, it falls to a value a factor of two below the th. ahold indicating that it is not clamped at the threshold value. Elcctron drift waves are generally driven by electron density or temperature gradients (Dominguez and Waltz (1987); Dorninguez (1989)]. In $\mathrm{H}$-mode discharges, the density proflle is generally flat and thus a mechanism dependent on electron temperature gradlents would be needed. In L-mode cllscharges the density profiles are peaked and thus electron drift waves could explain the difference between $\mathrm{L}-$ and $\mathrm{H}$-rnode confinement.

The $\mathrm{L}-$ to $\mathrm{H}$-mode transition has been studied in detail both to understand the differences in confinement under similar plasma conditions and to understand any thresholis in making the transition. The power threshold for making the $L$ to H transition is seen to depend line :rly on $B$ for. n'utral beam heating [Burrell (1980b)]. The dependence on feeld is seen with electron cyclotron heating by comparing resuits at first and second harmonic. This threshold power roughly doubles for hydrogen beams as compared to deuterium.

The $\mathrm{L}$ to $\mathrm{H}$ transition is cilaracterized by a sharp decrease in the edge magnetic and denisity fluctuations and a sudden increase in the poloidal rotation, along with the more conventionally expected decrease in the edge $D_{\alpha}$ radiation (Fig. 8). . Weasurements of density fluctuations made in the edge region of the DIII- D plasma show that there is a sharp decrease in the high frequency fluctuatiors localized to the outer 5 to $6 \mathrm{~cm}$ of the plasma following the $\mathrm{L}$ to $\mathrm{H}$ transition (Doyle (1990)! (Fig. 9). The typical t..ne scale for this decrease is $100-300 \mu \mathrm{s}$. This decrease in fluctuations is corisistent with more recent theories Shaing (1989); Biglari (1990)].

Over the past year, significant convergence has occurred between recent theories of the $L$ to $I I$ transition Shaing and Crume (1989); Biglari $(1990)^{\prime}$. The theories predict stabillation of edge

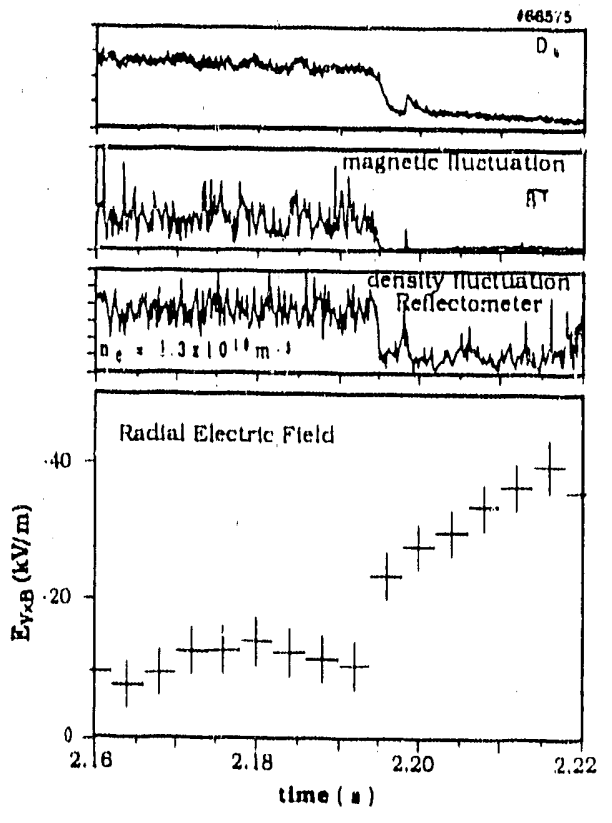

Fig. 8. The $D_{\alpha}$ radiation, magnetic fluctuations, and density fluctuations all decrease at the $H$-mode transaction ( $22.195 \mathrm{~s}$ ) while the radial electric field increases in this time segment of a typical L.H transition. 


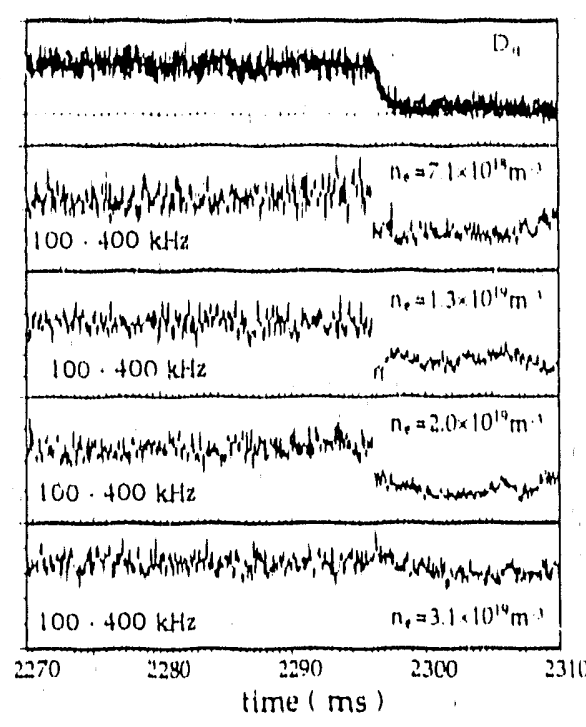

Fig. 9. The time evolution of the fluctuations mon. itored on four roflactometer channals during a transition, as well as a $D_{\alpha}$ photodiode sig. nal.
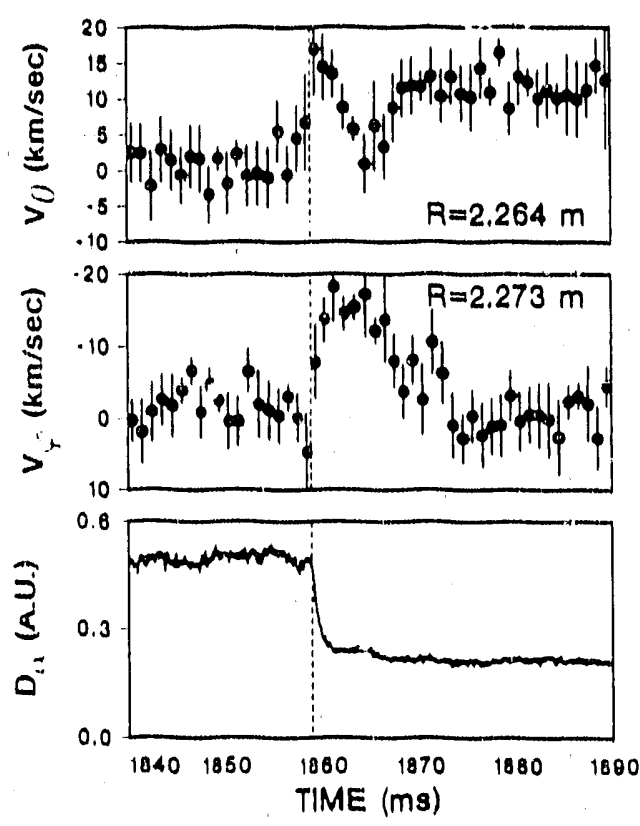

Fig. 10. The change in the toroidal $\left(v_{0}\right)$ and poloidal rotation $\left(v_{\phi}\right)$ near an $L-$ to H-mode tran. sition denoted by the sharp decrease in $D_{a}$ radiation from a DIII-D discharge.
Huctuations caused by shear in the polvidal rota. tlon at the plasma edige. The experimentally ob. served poloidal rotation varies signilficantly with position near the edge. Comparison of the rotalional shear with the stabillzation criterion given by Blglart (1900) Indicates that shear stabilization of the fluctuations is a reasonable conclusion (Groebner (1990), Matsumoto (1990)). In addiilon to the fluctuation stabilization mechanism, the work of Shaing and Crume sugesests that the bifurcation at the $L$ to $H$ transition is caused by a bifurcation in the poloidal rotation at the edge. The lon orbit loss at the plasma edge contributes an extra torque which, when coupled with the results of an improved calculation of neoclassical parallel viscosity, predlits a jump in the edge poloidal rotation at the transition. This extra torque should result in poloidal rotation speeds that are sienificantly larger than those predicted by standard neoclassical theory. This ump in the poloidal rotation at the transition has been clearly seseri experimentally (Fig, 10) and, in some cases, the change in the poloida rotation precedes the other signatures of the $L$ to II transition [Groebner (1990)). Finally, the observed rotation speeds are aboit a factor of 10 bigger than those predicted by standard neocinssical theory.

The transition into $\mathrm{H}$-mode has been observed using ECH power with the high field side 1st harmonic $X$-mode launch and in the earlier low field side lat harmonic $\mathrm{O}$-mode launch experiments [Lohr (1989)] and low field side second harmonic $X$-mode launch experiments iLohr (1989)]. The ECH power needed to make the transition into $\mathrm{H}$-mode increases linearly with toroidal field in agreement with data for neutral beam injection. The transition edge phenomena are also quartitatively similar including the presence of an increase in a radially inward electric fleld at the time of transition.

Proper conditioning of the vacuum vessel and the exclusion of unwanted impurities from the vacuum vessel by appropriate vacuum practices has bnen key to attaining high plasma performance and low $Z_{\text {eff }}$. This places particular imphasis on the need for next generation devices to provide the capabilities to ensure that these conditions can be met. In-vessel cleanliness is maintained by good high vacuum prat ice and the capability of baking the vessel to $400^{\circ} \mathrm{C}$ on an uvernight basis, Leaks as llttle as $2 \times 10^{-5}$ Torr-1/s are detrimental to plasma operation. Vessel wall conditioning [Jackson (1990a)], including most recently carbonization, has been key to attaining optimal plasma performance.

Carbonization of the acuum vessel surface has been used successfully in DIII-D to decretse the metal accumulation and high radiated power in high current deuterium discharges and thus reach new regirnes of high performance plasma operation Schissel (1990); Jackson (1090b); Winter (1989)! The application of methare glow discharge carbonization deposited a $60 \mathrm{~nm}$ carbon film over the surface of the vessel. This resulted in the reduction of metallic impurity influx by 
a factor of 30 and a substantal reduction in the radiated power (Fig. 11). Subsequent operatlon in deuterfum plasmas achieved currents up to 3 .MA with injected powers of up to 18 . MW. This resulted in DIII-D record high stored energies of $3.0 \mathrm{MJ}$ and beta values of greater than $5 \%$ at full toroldal field of $2,1 \mathrm{~T}$. Over the range $1 \leq l(M A) \leq 3$, the $\mathrm{H}$-mode power threstiold was not particularly different from prevlous results dlscussed above. Confinement thrie was seen to increase approximately linearly with current (Fig. 12) although thls Incrense ceases at the highest currents as was seen prior to carbonization Burrell (1989)!. This is Farticularly ovident in the power dependence where there is little to diferentate the post carbonization data at $\sim 2.8 \mathrm{MA}$ from the earlier data at $2.0 \mathrm{MA}(\mathrm{Fig}, 13)$.

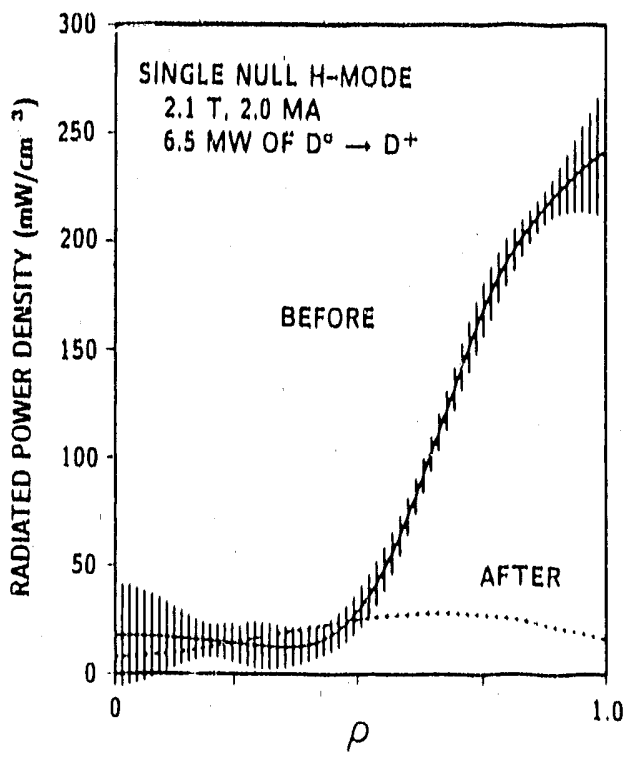

Fig. 11. Radiated power density profiles measured by a 21 channel bolometer diagnostic for two single-null $D^{\circ} \rightarrow D^{+} H$-mode discharg. es with and without carbonization. The vertical lines represent the typical error barid for these profiles.

\section{DIVERTOR AND EDGE PHYSICS}

Particular attention has been pald to demon. regimes for long pulse discharges anticipated in reactor devices. H-mode discharges have been operated for $10.3 \mathrm{~s}$ with $I_{p}=0.7 \mathrm{MA}$ and $-3.5 \mathrm{MW}$ of injected power (Fig, 14), and for $5 \mathrm{~s}$ with $L_{p}=1.25 \mathrm{MA}$ and $7.0 \mathrm{MIW}$ of power. Here the parameters of current and duration are set by the available power supplies and the beam power is adjusted to set the ELM frequency and achieve steady state as discussed below. Thuse discharge times are much longer than any of the character. istic plasma time constants. Near steady state plasma density, impurity content, and energy confinement time are achieved.

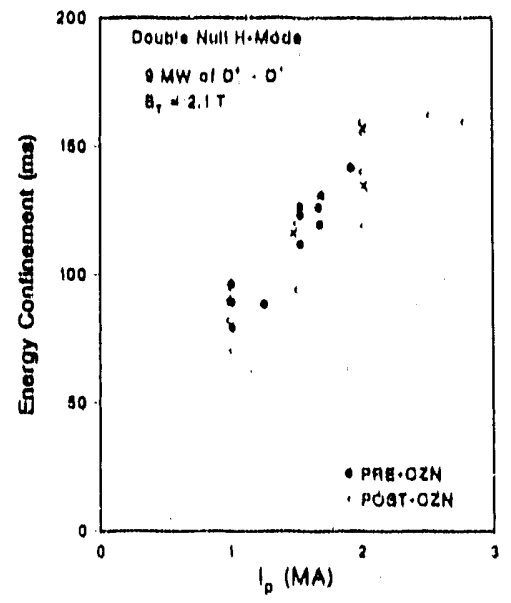

Fig. 12. TE versus total input power for discharges with and without carbonization.

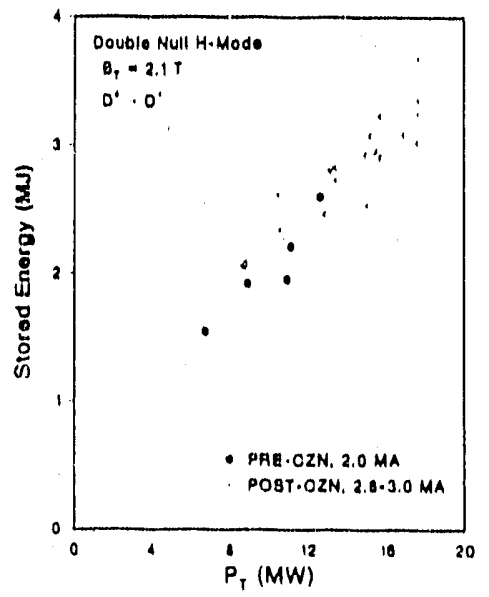

ig. 13. TE versus plasma current for discharges with and without cartonization.

Control of the ELMs is critical for the operation with these steady state plasmas since they determine the impurity accumulation and density rise in the plasma. Three types of ELMIs have been seen on DIII-D. The first is the so-called giant ELAl, and it is the most frequenty seen and best understood. There is considerable evidence that this ErMl occurs when the edge pressure 


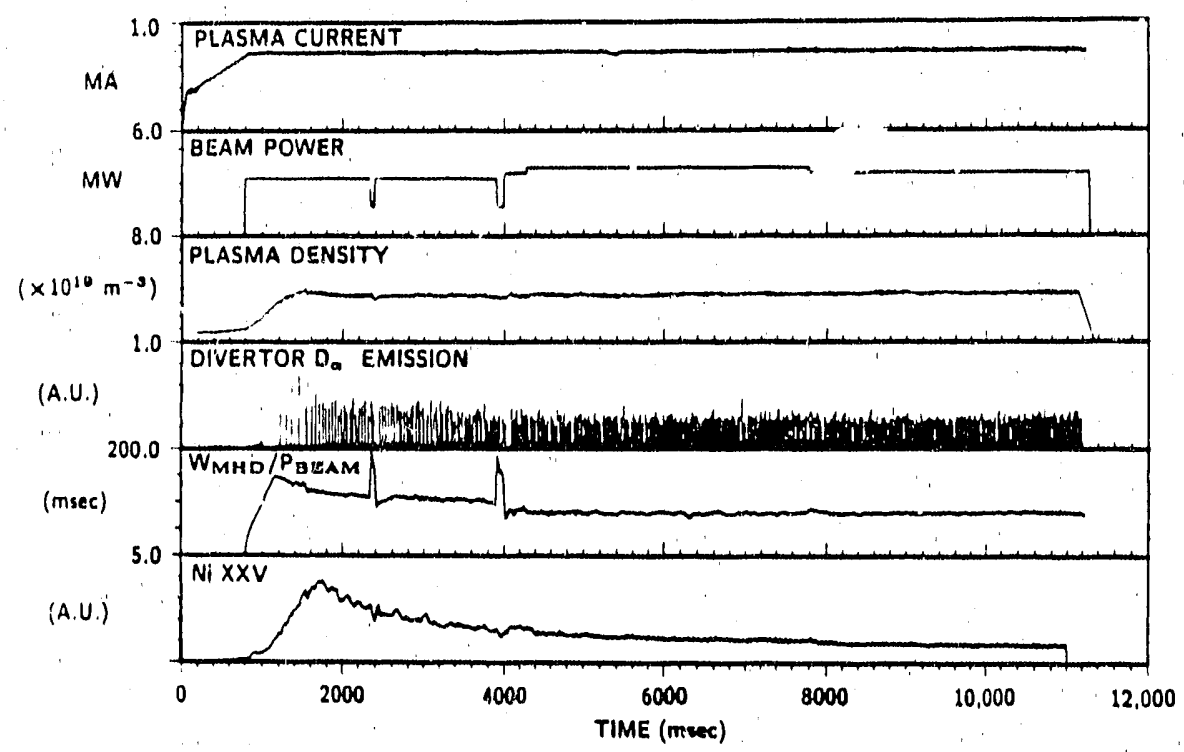

Fig. 14. A. DIII-D discharge demonstrating a $10 \mathrm{~s}$ period of $\mathrm{H}$-mode starting at $\sim 1 \mathrm{~s}$.

gradient reaches the ideal ballooning mode limit (Burrell (1989); Gohil (1988); Stambaugh (1988); Lao (1989); Ozeki (1989)]. Thus, the frequency of these ELMs increases with neutral beam power and decreases with plasma current. The second, the grassy ELM, is most easily seen when the plasma shaping produces edge conditions stable to ballooning modes [Ozeki (1989)]. The third is seen when the input power is $\mathrm{J}$ ust above the threshold power needed for $\mathrm{H}$-mode and it disappears with increasing input power. The frequency and duration of the giant ELMs can be used to control the accumulation of impurities in the discharge by carefully balancing the input power against the plasma current. This was the mechanism used to produce the near steady state conditions of Fig. 14. The balance near this optimum can be quite sensitive; a $16 \%$ decrease in the input power in near steady state discharges at $1.65 \mathrm{MA}$ resulted in severe imfurity accumulation and consequent disruption of the discharge.

Control of the frequency of ELMs using the localized deposition of ECH power near the plasma edge has been demonstrated. Control of the ELM frequency is important to managing long pulse $\mathrm{H}$-mode discharges because confinement and impurity accumulation both increase with decreasing ELill frequency. When ECH power is deposited well within the separatrix of a divertor H-mode discharge, the ELM frequency is seen to increase. However, when the power is deposited o itside the separatrix, the ELM frequency decreases by up to a factor of two with an attendant increase in energy ronfinement. One model proposed is that ELMs are triggered when the pressure gradient in the edge exceeds the critical pressure gradient for ballooning stability. The ECH may act to modify this pressure gradient when power is applied locally in the edge region.

Recent work on relating measurements made in the plasma boundary to applicable models is motivated by the need to develop validated models of the scrape-off layer plasma for use in predicting divertor conditions in next generation tokamaks [Hill (1990)]. A database of edge and divertor plasma parameters is being assembled for comparison with the Braams B2 code (Braams (1987)]. Much of the initial work has been done in L-mode discharges since they provide more nearly steady state conditions for the measurements. Langmuir probes spaced at $3 \mathrm{~cm}$ intervals across the bottom of the vessel provide divertor target plasma parameters (Buchenauer (1990)]. The heat flux is measured with an infrared TV camera. Thomson scattering provides edge plasma measurements near the midplane. The results from a series of these measurements are compared with the predictions from the B2 code in Fig. 15, where $\chi_{e}=4.0 \mathrm{~m}^{2} / \mathrm{s}, \chi_{i}=0.2 \mathrm{~m}^{2} / \mathrm{s}$, and there is a strong inward pinch required. From these results it can be seen that considerable progress in the modelling of the divertor heat fluxes has been made.

In single-null divertor discharges, the heat flux distribution is sharply peaked around the separatrix intercept points on the divertor target plates and the in/out symmetry in this heat fux distribution depends on the direction of the ion $\nabla \mathrm{B}$ drift relative to the $\mathrm{X}$-point position (Fig. 16). Heal flux 

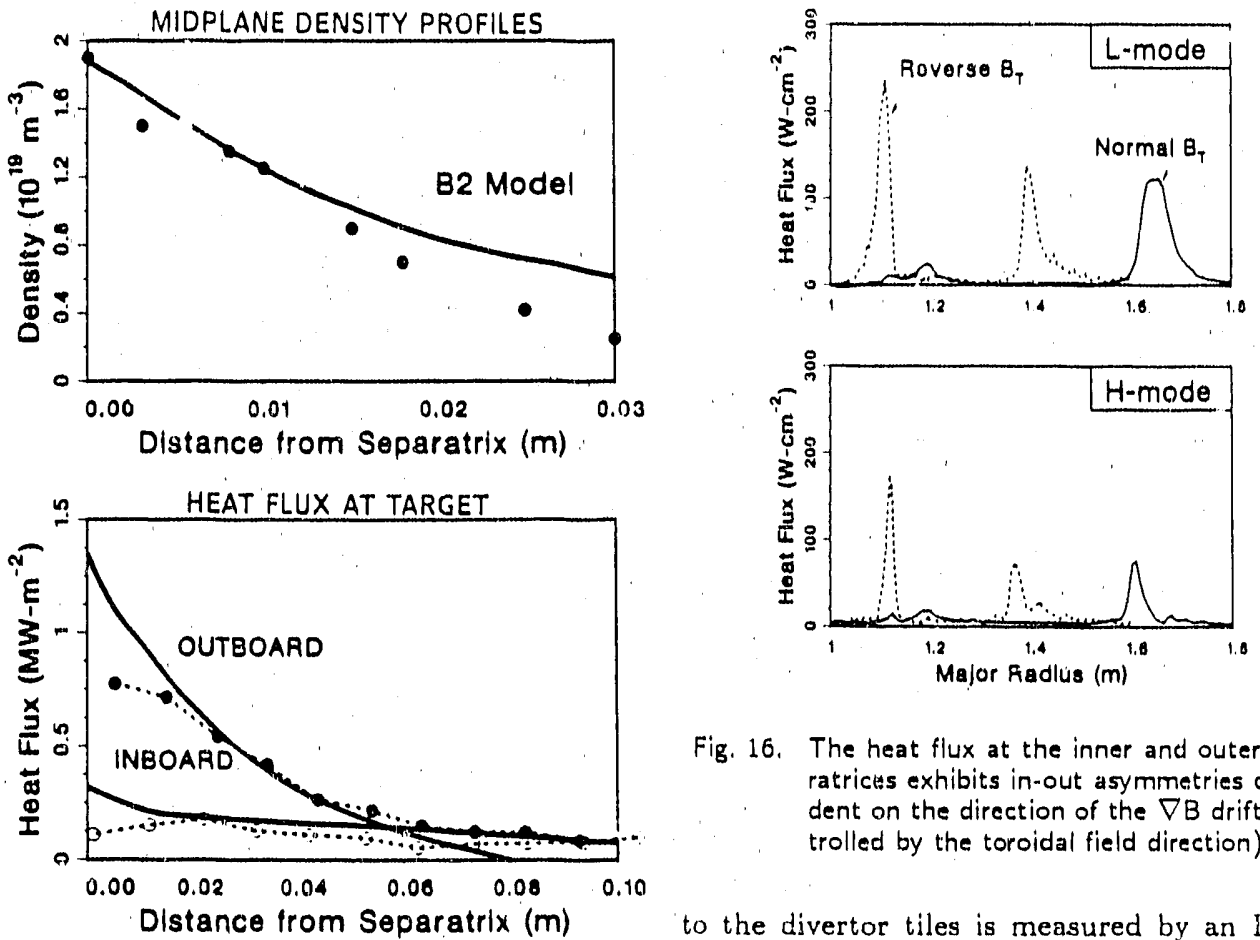

Fig. 16. The heat flux at the inner and outer separatrices exhibits in-out asymmetries deperident on the direction of the $\nabla B$ drift (controlled by the toroidal field direction).

to the divertor tiles is measured by an IR TV camera system [Hill (1988)], sensitive to radia. tion in the 8-12 $\mu$ range. With the ion $\nabla \mathrm{B}$ direction pointing towards the $\mathrm{X}$-point, more heat Hows to the outer intercept. This poloidal asymmetry in the total power can reach as high as 4. With the opposite toroidal field direction, the asymmetry in the total heat flux reverses. These observations are in qualitative agreement with the theoretical work of Staebler (1989), which considers asymmetries due to classical particle drifts. When the ion $\nabla B$ direction points toward the separatrix, increased particle flux into the inboard divertor leg enhances the p?ometrical effects to broaden and reduce the heat deposition on the inner tiles. The effect reverses with the opposite sense of the toroidal field.

The recent installation of detectors of the currents fowing through six tiles in a radial array across the lower divertor target region has yielded interesting initial results [Schaffer (1990)]. It is found that in single null divertors, current flows from the wall at the outer leg poloidally the long way around the plasma and back into the wall at the inner leg. The sum of the currents across the lower divertor region is zero indicating that the current flow is continuous in the boundary layer. In double null divertor discharges, the current flows principally in the outer boundary leg. The current does not flow in the private flux region under the $X$-point.

The currents in the scrape-off layer are seen to increase with both plasma current and neutral beam power. Figure 17 shows data from a single-null beam-heated divertor plasma with $\nabla B$ toward the $X$-point, a current of $\simeq 2 \mathrm{kA}$ flows in the SOL plasma from the inner (colder) divertor leg to the outer (hotter) divertor leg. At the $\mathrm{L}-$ to $\mathrm{H}$-mode transition the currents are generally seen to decrease. As a result of the heat flux imbalance between the two legs of the divertor discussed above, a thermo-electrically driven current is predicted to flow from one divertor leg to the other [Harbour (1989); Staebler (1989)]. The direction and magnitude of the observed current are in agreement with the predicted thermoelertric effects [Staebler (1989)]. During large EI.AIs, particularly large currents of up to $10 \mathrm{kA}$ are seen to flow.

Two techniques, gas injection and divertor sweeping, have been studied for managing the flow of heat into the divertor region. The gas injection experiments, while preliminary, demonstrate the potential for controlling divertor target heat fux through the use of gas puff into the divertor region to enhance radiation. Injection of gases into the region below the $X$-point of single null divertor discharges has been successfully used to increase radiation from the boundary region and 


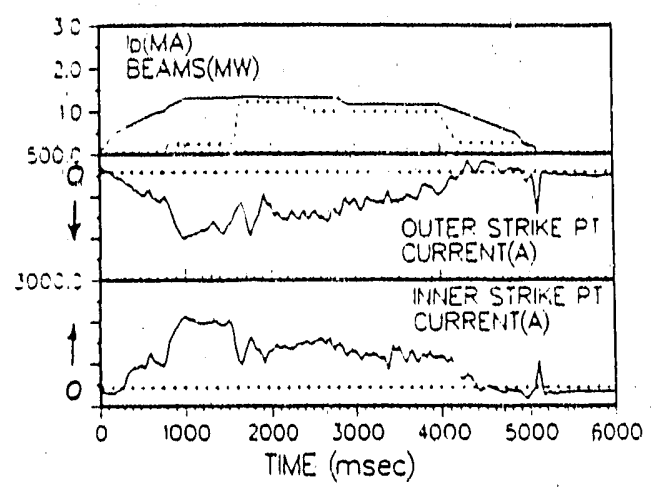

Fig. 17. Time histories of discharge parameters shovs. ing current flow in the plasma boundary of a single-nulf divertor discharge. The current flows out of the target near the inner strike point around the main discharge and returns at the outer strike point. The plasma enters $\mathrm{H}$-mode at $\sim 1600$ ms:

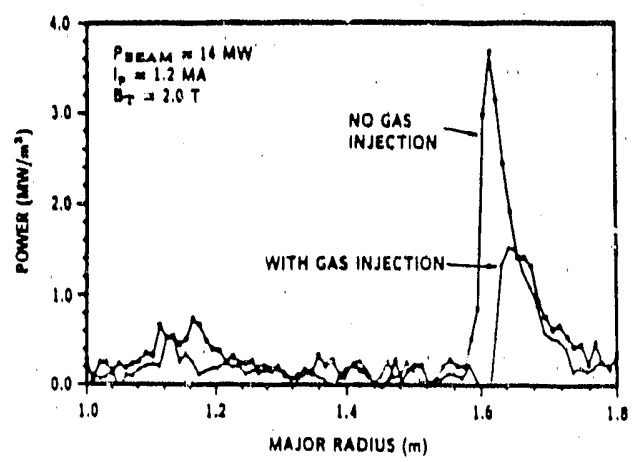

Fig. 18. Heat loads across the divertor target of DIII-D during an $\mathrm{H}$-mode single-riull divertor discharge demonstrating the reduction in the peak heat load by deuterium gas injection outside the $X$-point.

The divertor peak heat load has been reduced by a factor of three by sweeping the divertor $X$-point location. This was demonstrated in single null discharges by modulating the input to the control program for the adjacent coils [Hill (1990)]. The MiHD separatrix flux surfaces for the extremes of the $\pm 6 \mathrm{~cm}$ sweep are shown in Fig. 20(a), and the time dependence of the resultant peak heat flux from IR camera merisurements is shown in Fig. 20(b). This sweeping was accomplished without significantly affecting the other key features of the plasma shape, the plasma density, the impurity accumulation, or the confinement time. Control schemes have been developed for double null divertor discharges which are effective in distributing the heat load between the two nulls by adjustment of the boundary flux values. consequently reduce the heat load to the divercor plates. Initial experiments have been carried out using deuterium and nitrogen gases injected from a single toroldal location on the vessel floor below the $\mathrm{X}$-point.' Deuterium gas was injected at a rate of 120 Torr $1 / \mathrm{s}$ into a single null divertor discharge with $14.5 \mathrm{MW}$ of t.autral beam heating (Fig. 18), The heat flux is highest at the outer leg of the separatrix. Following gas injection, this heat flux decreases from $4 \mathrm{MW} / \mathrm{m}^{2}$ by more than a factor of two. An increase is seen in the radiation from the divertor region. The plasma properties vary only slowly over the one second duration of the gas injection. The energy confinement time decreases slightly, $Z_{\text {eff }}$ drops, and the density increases.

Experiments injecting impurity gas are noteworthy because they provided dramatic control of the heat flux to the target with little if any increase in the plasma density, but with only a modest rise in the impurity content of the bulk plasma. Experiments were carried out injecting nitrogen gas into $1.2 \mathrm{MA}$ discharges with up to $20 \mathrm{MW}$ of neutral beam power. The target heat flux was reduced hy a factor more than 2 from $3 \mathrm{MW} / \mathrm{m}^{2}$. while the energy confinement time decreased by only $5 \%-15 \%$ and $Z_{\text {eff }}$ increases to 2.4 compared to 1.8 in a comparable discharge with no nitrogen injection (Fig. 19).
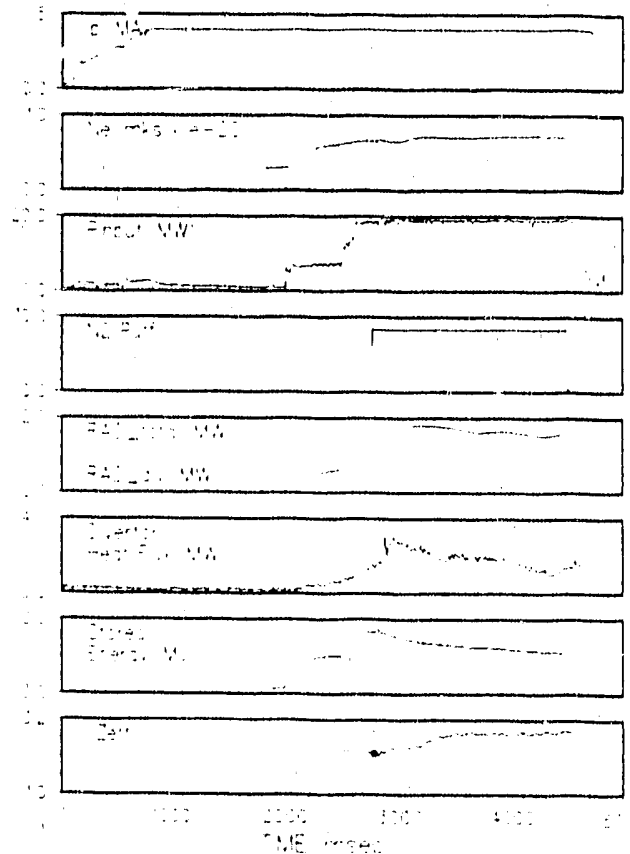

ig. 19. Characteristic plasma parameters for a discharge with nitrogen injection outside the $x$-point showing the divertor heat flux drops by a factor of more than two. Nitrogen injection level is in Torr-1/s. 
EFITD Plasma Equilibrium

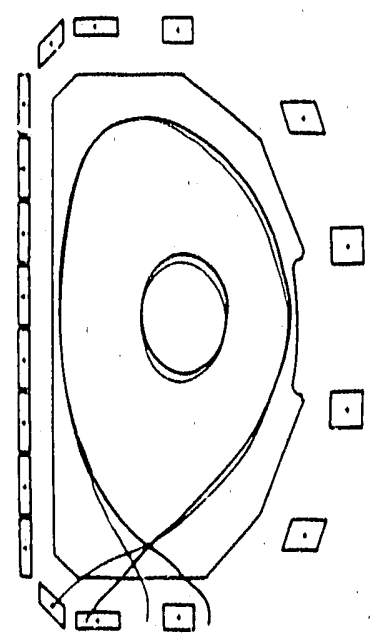

Divertor-Tile Surface Temperature

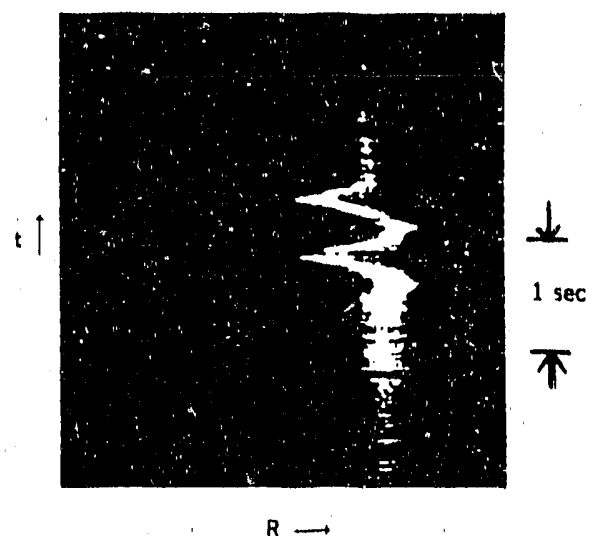

$R \rightarrow$

Fig. 20. Demonstration of heat load spreading on the divertor plate achieved by sweeping of the separatrix location. (a) The plasma equilibrium separatrix flux surface at the inriermost and outermost extremes of the sweep showing the range over which the hot spot on the divertor target (bottom) is swept. (b) The time history of the hottest spot in the outer strike region of the divertor target plates as seen by an IR camera showing the radial displacement achieved during sweeping.

\section{CURRENT DRIVE}

Establishing the needed current drive techniques for steady state plasma operation remains a key goal in the DIII-D program. While progress has been made towards this goal, definitive answers to many questions, including in particular the identification of optimal techniques for achieving current drive in energetic plasmas, await high power experiments.

Electron cyclotron current dri $\because$ experiments have been performed using $\mathrm{X}$-mode waves at $60 \mathrm{CHz}$ launched from the high field side of the torus [Jarnes (1990)]. Between $50 \mathrm{kA}$ and $100 \mathrm{kA}$ was driven by electron cyclotron waves in discharges with between $200 \mathrm{kA}$ and $500 \mathrm{kA}$ total current. These experiments are the first to be done in plasmas with strong single pass absorption ( $99 \%$ ), and slowing down times for the current carrying superthermal electrons which are much shorter than the energy confinement time. An example is shown in Fig. 21 in which the plasma current was maintained constant at $400 \mathrm{kA}$ and $1.2 \mathrm{MW}$ of $\mathrm{rf}$ power was applied. The line-averaged electron density was $\bar{n}_{e} \sim 1.5 \times 10^{19} \mathrm{~m}^{-3}$. The of driven current was determined after first correcting for the change in the plasma resistance using a $1 D$ transport code. Bootstrap currents, accounting for less than $10 \%$ of the total current, were included. The result is that the driven current is about $70 \mathrm{kA}$. Estimates made using a bounce-averaged Fokker-Plank code [Giruzzi (1988)] indicate a current of $95 \mathrm{kA}$. These results were also confirmed in a similar example with the relative direction of the driven current reversed which had the result that a similar driven current in the opposite direction was seen.

Work on neutral beam current drive has concentrated primarily on the behavior of these discharges at high $\beta_{p}$. In addition, we have hegun the study of the self-consistent evolution of fully noninductive discharges (with only NBCD and bootstrap current). Double-null divertor discharges $\left(\kappa \sim 1.9, I_{p}=500 \mathrm{kA}, \mathrm{H}\right.$-mode $)$ have been established with $\beta_{\mathrm{p}}=5.1$ and $\epsilon \beta_{\mathrm{p}}=1.8$, using up to $14 \mathrm{MW}$ of neutral beam injection (Fig. 22). During the ELM-free phase, excellent $\mathrm{H}$-mode confinement is obtained $\left(\tau_{\mathrm{E}} \sim 2.3 \times \pi_{\text {TER }}-\mathrm{P}\right.$ ), reaching stationary pressure conditions. Wher $\beta_{\mathrm{p}}>$ 1, fishbone-like bursts of MHD activity occur, affecting the radial distribution of fast ions. These oscillations have $m / n=4 / 1$, with a strong $2 / 1$ component. The stability of one such discharge to high $n$ localized ballooning modes has been analyzed using the CAMINO code (Whance (1.987): Fig. 23 summarizes the results for the full plasma cross-section. For each flux surface, the shear and pressure gradient are normalized to display the same stability limit curve, and the locus of points corresponding to the measured plasma profile is shown. For the est mated range of ro (2 to $3)$, the entire plasma is in the region between first and second stability, where there is no limiting pressure gradient. During the ELill-free phase of these high $\Theta_{p}$ discharges, the loop voltage is 

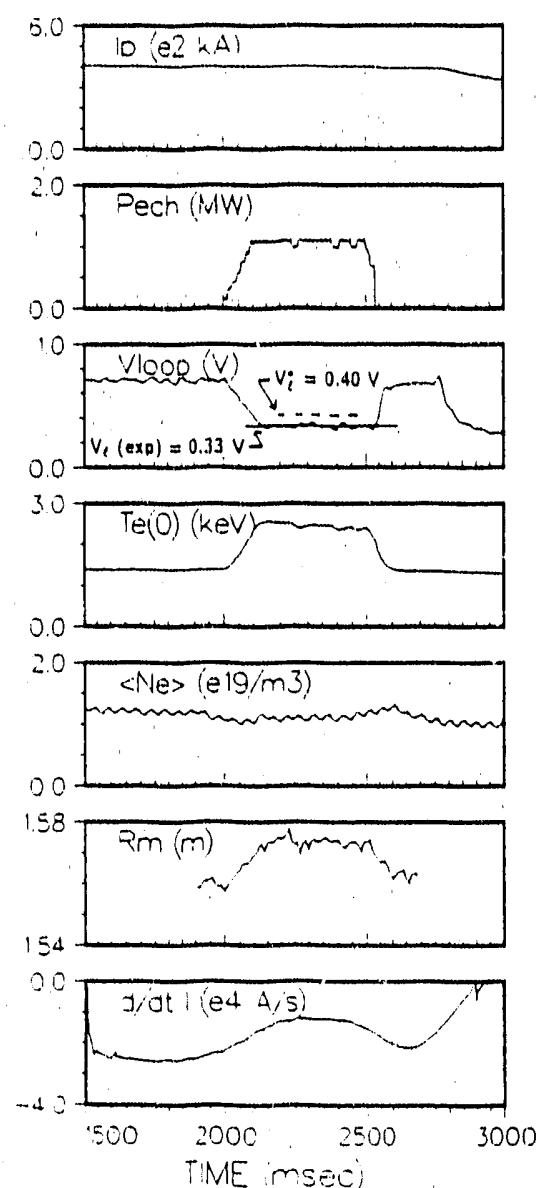

Fig. 21. Time evolution of the plasma parameters of a DIII...D discharge during ECII heating. The calculated loop voltage in the absence of current drive is shown dotted.

negative, but there is insufficient time to reach a stationary state and transient analysis of the current profile evolution is required. After the onset of ELMs, a stationary state is reached with positive voltage. For typical $500 \mathrm{kA}$ discharges, there is a $35 \%$ bootstrap fraction and $10 \%$ residual ohmic current (the remainder is bearn-driven).

Hardware is currently (July 1990) being installed to carry out ion cyclotron fast wave current drive experiments with $2 \mathrm{MW}$ of power. The large ports in DIII-D allow us to install a four element fast wave current drive array. A key feature of these experiments will be the use of ECH power

to heat the electrons and thus improve the efficiency by increasing electron temperature and beta. The installation of a current carrying ring electrode in the bottom of the vessel will also allow a test of current drive using helicity injection.

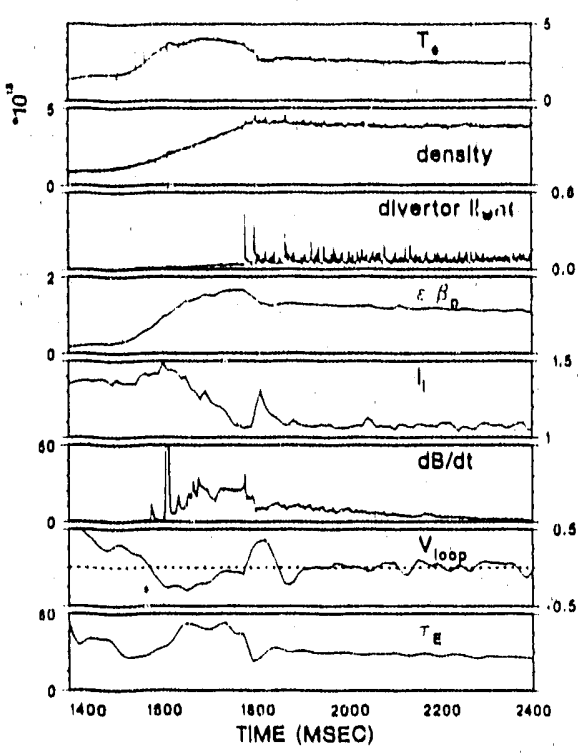

Fig. 22. A portion of the time history of discharge 67700 . NBI begins at $1500 \mathrm{~ms}, \epsilon \beta_{p}$ reaches 1.0 at $1605 \mathrm{~ms}$, and the very high $\epsilon \beta_{p}$ phase ends with the large ELM at $1775 \mathrm{~ms}$.

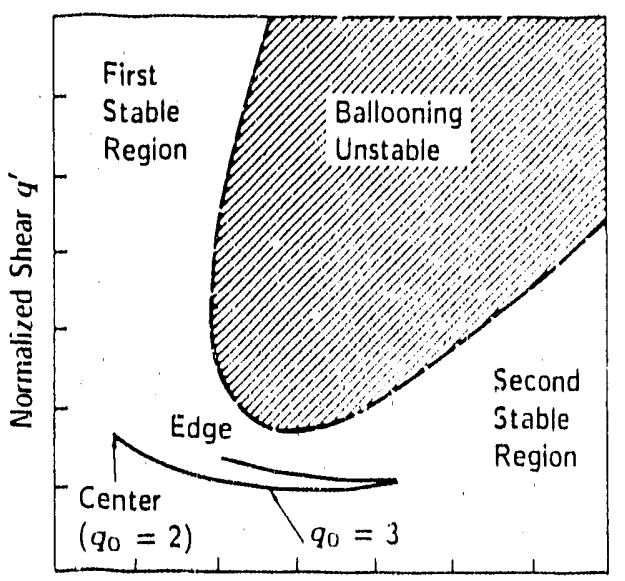

Normalized Pressure Gradient, $\rho^{\prime}$

Fig. 23. The calculated plasma profile of shear versus pressure gradient as a function of the plasma cross section for a high $\beta_{p}$ discharge compared to theoretically anticipated stability regimes. 


\section{RF HEATING PHYSICS}

High power Ion Bernstein Wave (IBW) experiments have been carried out in an attempt to develop an efficient mechanism to couple of power in the ion cyclotron frequency range to $\mathrm{H}$-mode divertor plasmas (Brambilla (1988); Chiu (1989)|. Earlier experiments using limiter plasmas have reported ion heating [Ono (1985); Moody (1988)], and Improved particle confinement and ion energy confinement have also been obtained [Ono (1988), Moody (1989)]. However, no evi. dence of efficient central heating has been found in high power experiments on the larger DIII-D tokarnak [Pinsker (1989)]. Rather, perpendicular ion heating is observed in the edge plasma under conditions where coupling to the IBW is expected. Evidence for parametric decay has also been observed using rf probes in the edge plasma. Most importantly, this decay has been correlated with the edge ion heating. Antenna loading measurements have shown that the antenna coupling characteristics are in disagreement with the linear theory for direct IBW excitation (Brambilla (1988); Chiu (1989)]. These results indicate that efficient coupling to IBWs which propagate to the center of the plasma may be prevented by non-linear mechanisms in the edge (Porkolab (1990)].

The IBW antenna is a movable end fed loop antenna mounted at the outer midplane of the torus. The experiments were carried out with up to $1 \mathrm{MW}$ of power in the frequency range 30 to $60 \mathrm{MHz}$. Most of the experiments reported here were carried out in the regime in which the $\omega=(3 / 2) \Omega_{H}$ majority $\left(\omega=3 \Omega_{D}\right.$ minority) resonance is located in the center of the plasma with $\mathrm{B}_{\mathrm{T}}=1.8 \mathrm{~T}$, and the $2 \Omega_{\mathrm{H}}$ layer is located behind the radiating element of the antenna. This satisfies theoretical conditions for efficient coupling to IBWs.

A number of non-linear edge plasma interactions have been produced by the coupling of IBWV power to the plasma. Parametric decay of the pump wave into multiple decay waves has been observed with of probes at the plasma edge (Fig. 24); these decay products likely are ion Bernstein waves, ion cyclotron quasi-modes, and harmonic generation which may be due to rf sheath effects. The parametric decay waves are at maximum amplitude at the toroidal field corresponding to conditions for direct coupling of IBWs. Perpendicular edge ion heating (Fig. 25) has been correlated to the presence of lon cyclotron quasi-modes using hydrogen gas puffing and toroidal field scans.

DIII-D has demonstrated the use of ECH power both to preionize the plasma and effectively reduce the electric field required at plasma initiation and to demonstrate that initiation can be obtained in the presence of substantial transverse magnetic field [Lloyd (1990)]. This is important in the design of next generation devices because of the high cost of the power systems to provide this electric field, and because of the slow penetration times and high transverse fields resulting from the use of relatively thick metallic vacuum vessels and related structures.

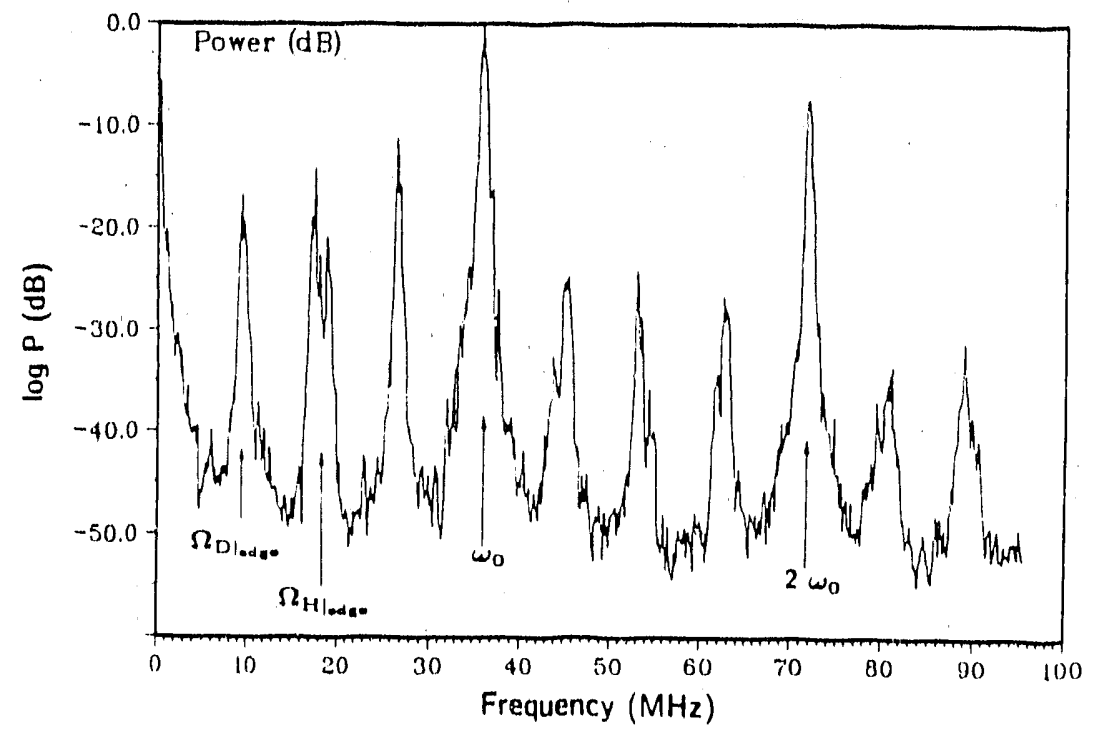

Fig. 24. Parametric decay spectrum measured during $0.8 \mathrm{MW}$ IBW injection. Peak at the $36 \mathrm{MHz}$ generator frequency is saturated for clearer display of decay wave peaks. 
The application of $700 \mathrm{~kW}$ of ECH power has allowed prompt and robust initiation of discharges with as title as $0.3 \mathrm{~V} / \mathrm{m}$ in the presence of transverse flelds as high as 40 gauss $\left(\mathrm{B}_{\mathrm{T}}=2.1 \mathrm{~T}\right)$ (Fig. 26). Without ECH, initiation at these electric flelds could only be achieved with carefully minimized transverse fields and it was characterized by substantial delays in the current rise. The application of ECH power over the first $500 \mathrm{~ms}$ of the 1 sec discharge current ramp up resulted in negligible reduction in the flux from the ohmic heating transformer, and there was little offect on the impurity content of the resultant discharge.

\section{SUMMARY}

The DIII-D results reported here are strongly supportive of designs for next generation tokamaks, particularly ITER and CIT. Understanding of experimental results for plasma stability and limiting beta values have established that the needed plasma regimes should be attainable. Limiting beta values have been demonstrated to be at least as high as $\beta=3.5 \mathrm{I} / \mathrm{aB}$ over the range $0.5<$ $\mathrm{I} / \mathrm{aB}<3.1$ with values as high as $\beta=5 \mathrm{I} / \mathrm{aB}$ demonstrated for $\mathrm{I} / \mathrm{aB}$ near 1.1 . Beta values as high as $10.7 \%$ have been attained it $3.1 \mathrm{I} / \mathrm{aB}$. Designs for both ITER and CIT anticipate $\beta=$ $3 \mathrm{l} / \mathrm{aB}$ as an upper limit and operuting beta values of $5 \%$ to $6 \%$. Understanding of disruptions particularly the large forces on thi: vesse structure, provides important input to the design of these devices.

Recent results on the dependence of confinement time on plasma size along with understanding of current and power dependence, extrapolate favorably to ITER and CIT. Analysis of DIII-D and JET ELM-free $\mathrm{H}$-mode discharges has shown confinement increasing as $\mathrm{R}^{1.5}$. This result indicates that adequate confinenert will be avalable for ITER and CIT, but it is optimistir in that it considers only ELM-free H-mode discharges and more detailed dependences on density, aspect ratio, and magnetic field remain to be determined. Understanding of plasma transport is evolving and short wavelength turbulence is emerging as dominant in determining transport properties. Theories incorporating short wavelength turbulence are consistent in key areas with results for plasma transport and the behavior of plasma edge parameters.

Techniques for controlling impurity influx and the boundary heat flux have been demonstrated $\mathrm{H}$-mode discharges of $10 \mathrm{sec}$ duration have demonstrated that near steady state particle and impurity balance can be maintained. Control of impurities has been demonstrated through management of the edge instabilities (ELMs) and divertor gas injection. Reduction of the boundary heat flux has been demonst; ated using
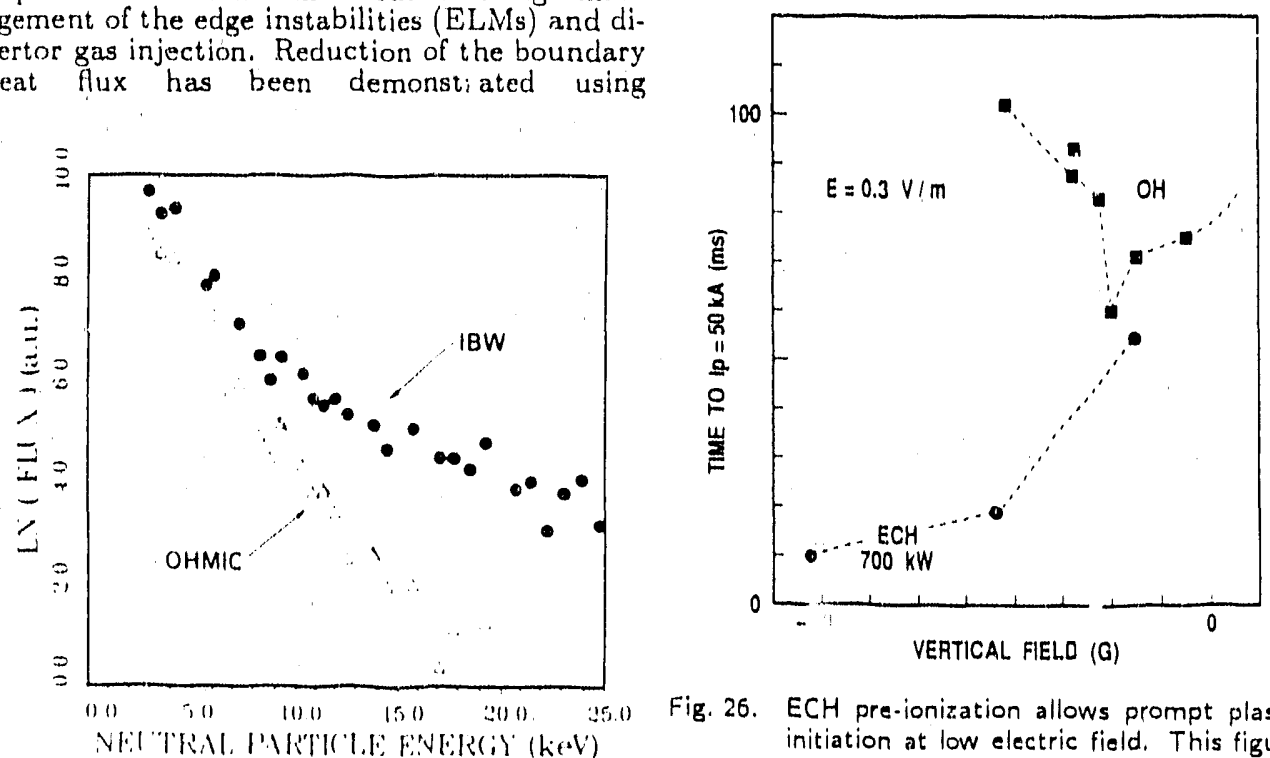

Fig. 25. Charge exchange neutral hydrogen spectrum showing perpendicular tail formation during IBW. Lower energy channels $(E<15 \mathrm{keV})$ contain significant spillover from deuterium channels $[H /(H+D) \sim 3 \%]$

Fig. 26. ECH pre-ionization allows prompt plasma initiation at low electric field. This figures shows the time required to reach a plasma current of $50 \mathrm{kA}$ as a function of vertical field witil a one-turn voltage of $0.3 \mathrm{~V} / \mathrm{m}$ applied with and without $(\mathrm{OH}) 700 \mathrm{~kW}$ of ECH power applied. Initiation could not be achieved without $\mathrm{ECH}$ power outside the range shown. 
divertor sweeping and divertor gas injection. Understanding of the boundary region is emerging both through theoretical understanding of newly availab!e edge data and modeling of edge phenomena.

Single and double null divertor discharges have been compared on the basis of limiting beta values, confinement and edge boundary behavior. Beta values approaching $3.5 \mathrm{l} / \mathrm{aB}$ can be achieved in both single null and double null divertor discharges over a wide range of curretit. Double null discharges can attain higher values of $1 / a B$ within the constraint $q_{95}>2$ and thus have reached higher values of beta. Confinement in $\mathrm{H}$-mode divertor discharges does not depend measurably on single or double null configuration although confinement values can depend on the precise location of the separatrix in a given config:uration especially through modification of the behavior of the edge instabilities (ELMs). The increase in cunfinement with plasma current is seen to saturate at the highest currents resulting in no confinement advantage being gained from the high current capability of double null configurations. Double null divertor configurations allow the heat load to the target to be potentlally spread out over a larger area, and the ability to balance these heat loads has been demonstrated. However, this may be offset by the greater flexibility in managing the heat load afforded by the single null configuration.

Extensive experiments using high power IBW heating have resulted in no observed bulk lon heating. Evidence from parametric decay and edge lon heating indicate that propagation to the center : the plasma may be prevented by nun-linear mechanisms in the edge.

Electron cyclotron current drive e:periments with $1.2 \mathrm{MW}$ of power at $60 \mathrm{GHz}$ have resulted in $70 \mathrm{kA}$ of driven current in $400 \mathrm{kA}$ discharges. This result is consistent with estimates from a bounce averaged Fokker-Planck code.

\section{ACKNOWLEDGMENT}

This work was supported by the II.S. Department of Energy under Contract No, DE-A.C0389ER51114.

\section{REFERENCES}

Biglari, H., et al., Phys. Fluids B2, (1990) 1.

Brnams, B.J., "A Multi-Fluid Code for Simulation of the Edge Plasma in Tokamaks," NET Report. VR.68 (1987)

Brambilla, .M., Nucl. Fusion 28, (1988) 549.

Buchenauer, D., et al., J. Nucl. Materials to be published.

Burrell, K.H., et al., Plasma Physics and Controlled Fusion 31., (1989) 1649.

Burrell, K.H., et al., Plasma Phys, and Contr. Nucl. Fusion Research 1, (1989) 193.

Burrell, K.H., et al., Proceedings of the Seventeenth European Conference on Controlled Fusion and Plasma Heating, Ansterdam, Vol. 1, (18,j0) 271.

Chance, M.S., International Sch of Plasma Physics, Theory of Fusion Plasma, Varenna Italy (August, 1987) 87.

Chang, C.S., F.L. Hinton, Phys. Fluids 25, (1982) 1493.

Chiu, S.C., et al., General Atomics Report GA-A19600 (1989), submitted for publication in IEEE Trans. on Plasma Science.

Colleraine, A.C., et al, in Proceedir.gs of the Eleventh Symposium on Fusion Engineering, ( $E E E E$, Vew York, 1985), Vol. 2, 1278 .

Dominguez, R., R. Waltz, Nucl. Fusion 27, (1987) 65.

Dominisuez, R., General Atomics Report GA-A19531 (May, 1989).

Doyle, E.J., et al,, "Density Fluctuation Measurements via Reflectometry on DIII-D During Land H-mode Operation," Proceedings of the Seventeenth European Conference on Controlled Fusion and Plasma Heating, Amsterdam, Vol. 1, (1990) 203.

Ferron, J.R, et al., Phys. Fluids B2, (1990) 1280.

Ferron, J.R., et al., Proceedings of the Seventeenth European Conference on Controlled Fusion and Plasma Heating, Amsterdam, Vol. 1, (1990) 371.

Giruzzi, G., Phys. Flluid.s 31, (1988) 3305.

Gohil, P., et al., Phys, hev. Lett. 61, (1988) 1603.

Groebner, R.J., et al., "The Role of Edge Electric Field and Poloidal Rotation in the L-H Transition." submitted to Physical Review Letters (1990).

Harbour, P.J., et al., J. Nucl, Woter. 162-184, (1989).

Hill, D.V., et al., Rev. Sci. Instm.m. 50, (1988) 1878.

IIill, D...., et al., J. Vucl. Mater, to be published. 
Hill, D.N, et al, General Atomics report GA-A2018: to be submitted to Nucl, Fusion.

Jackson, G.L., et al., General Atomes Report GA-A19891 (1990)), submitted to Nucl. Fusion.

Jackson, G.L., et al., "Carbonization of the DIII--D Tokamak" to be published in the Journal of Nuclear Materials (1990).

James, R.A., et al. Proceedings of the Seventeenth European Conference on Controlled Fusion and Plasma Heating, Amsterdam, Vol, 3, (1990) 1259.

Jerisen, T., M. Chu, Phys. Fluids B 1, (1989) 1545.

Kive, S.M., R.J. Goldston, Nucl. Fusion 25, (1985) 65.

Keilhacker, M., et al., Plasma Physics and Controlled Nuclear Fusion Keseareh, (Proceedings of Tenth International Conference, London, 1984), LAEA, Vlenna (1985), Vol, l, p. 71.

Kim, J, et al., Proceedings 12rh symp on Fusion Englneering, Monterey 1, 290, IEEE, New York (1987).

Lazarus, E.A., et al, Proceedings of the Seventeenth European Conference un Controlled Fusion and Plasma Heating, Amsterdam, Vol. 1, (1000) 427.

Lao, L. L, et al., Nucl. Fitsion 25, (1985) 1611 .

Lao, L.Li, et al., Plasma Physics and Controlled Fusion 31 (1989) 509.

Lao, L.L., et al, submitted to Nuclear Fusion.

Lao, L.L., et al." "Vertical Forces on Vacuum Vessels of Elongated Tokamaks After Loss of Verticul Stability," General Atomics Report GA-A20101; to be submitted to Nuclear Fusion.

Lohr, J., et al., "Recent Electron Cyclotron Heating Experiments with Low Field Launeh of t te Ordinary Mode on the DIII-D Tokamak," GA-A19634.

Lohr, J., et al., Phy. Rev. Lett. 60, 2630 (1988).

Luxon, J.L., L.G. Davis, Fusion Technol. 8, (1985) 441.

Lloyd, B., et al., to be published:

Mahdavi, M.A., et al, to be published in J. Nucl. Materials.

McGuire, K., et al, Plasma Physics and Contro!led Nuclear Fusion Research, (Proceedings of the Eleventh Intersiationai Conference, Tok:'o, 1086), IAEA, Vienna (1987), Vol. I, p. 428.

Mood, J.D., et al. Phys. Rev. Lett. 60, (1988) 293.

Okabayashi, M., et al., Plasma Physics and Controlled Nuclear Fuoion Research. (Proceedings of the Zleventh International Conference, Tokyo, 1986), LAEA, Vienna (1987), Vol. I, p. 279.

Ono, Ml, et al., Phys. Rev, Lett, 54, (1985) 2339.

Ozeki, et al., "Plasrua Shaping, Edge Ballooning Stability, and ELM Behavior in DIII-D," General Atomics Report GA-A19495 (June 1989).

Pinsker, R.J., et al., in Radio-Frequency Powering Plasmas, (Eighth Topical Conference, Irvine, California 1989), AIP Conference Proceedings 190, New York, 1989, p. 31.4.

Porkolab, M., Fusion Engineering and Design 12, (1990) 93.

Romanelli, F., Phys. Fluids B 1, (1989) 1018.

Schaffer, M.J., B.J. Leikind, "Observation of Clrculating Currents in Tokamak Scrape-Off Layer," General Atomics report GA-A20128.

Schissel, D.P., et al., General Atomics reporc GA-A19025, submitted to Nurlear Fusion.

Shaing, K.C., Fi.C. Crume, Jr., Phws. Rrv. L...t. B3, (1989) 2369.

Staebler, G.H., F.L. Hinton, Nucl. Fusion 20, (1089).

Staebler, G.H., F.L. Hinton, General Atomics report G.A-A 19516 (1980).

Stambaugh, R.D., et al., Plasma Physics and Controlled Vuclear Fusion Reyearch, (Proceedings of Tenth International Conference, London, 1984), IAEA, Vienna (1085), Vol. I, p. 217.

Strait, E.J., et al., General Atomics report to be published.

Sykes, $A_{\text {, }}$ et al., in Proceedings of Eleventh European Conference on Controlled Fusion and Plasma Physics, Aachen (EPS, Petit-Lancy, Switzerland, 1983), Vol, 2, p. 363.

Stambaugh, R.D., et al, in Proceedings of Fifteenth Europena Conference on Controlled Fusion and Plasma Heating, Dubrovnik, Yugoslavia, 1988, Vol. 30.

Troyon, F., et al., Plasma Physics Contrulled Fusion 20, (1984) 209

Winter, J., J. Nucl. Water. 101, (1989) 265. 

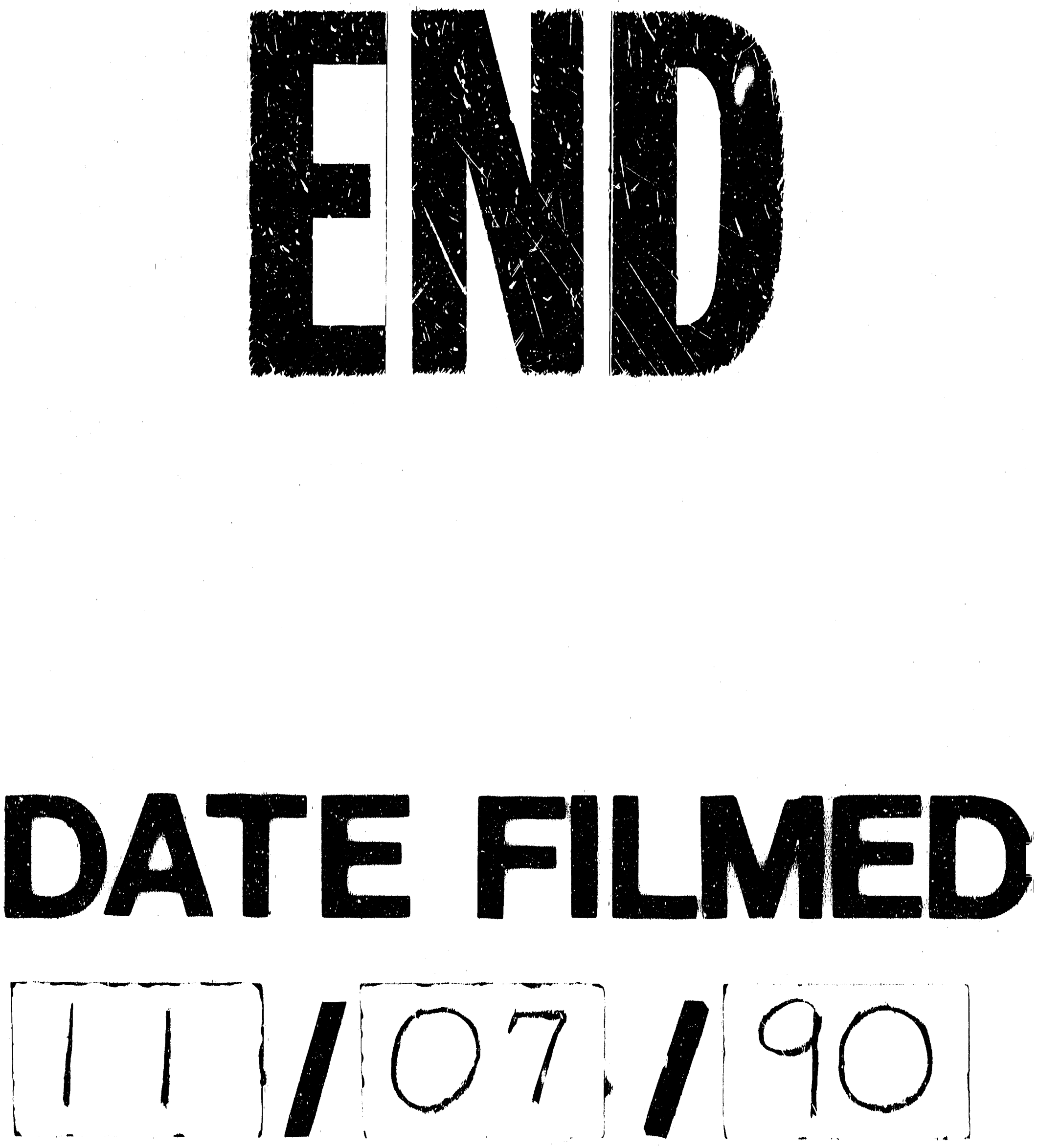
